\title{
Selection of the optimal herbal composition of pomegranate concentrated powder from aqueous extracts of Eucommiae Cortex and Achyranthis Radix to treat osteoarthritis in rats
}

\author{
Beom-Rak Choi ${ }^{1,2}$, Sae-Kwang Ku ${ }^{3,4}$, Su-Jin Kang ${ }^{4,5}$, Hye-Rim Park ${ }^{1}$, Mi-Sun Sung ${ }^{1}$, \\ Young-Joon Lee ${ }^{4,5}$, Ki-Moon Park ${ }^{2}$ \\ ${ }^{1}$ Research Institute, HL Science Co., Ltd. \\ ${ }^{2}$ Department of Foodscience and biotechnology, Sungkyunkwan University \\ ${ }^{3}$ Department of Histology and Anatomy, College of Korean Medicine, Daegu Haany University \\ ${ }^{4}$ The Medical Research Center for Globalization of Herbal Medicine, Daegu Haany University \\ ${ }^{5}$ Department of Preventive Medicine, College of Korean Medicine, Daegu Haany University
}

Objectives: We investigated whether a mixture of the main component of pomegranate concentrated powder (PCP) with appropriate proportions of Eucommiae Cortex (EC) and Achyranthis Radix (AR) could act synergistically as an effective treatment for osteoarthritis (OA).

Methods: In order to evaluate the effects of PCP, EC, and AR against OA, knee thicknesses, maximum extension angle of each knee, anti - inflammation effects, the transcript levels of chondrogenic genes mRNA expressions in femur and tibia articular cartilage (AC) with synovial membrane (SM) were analyzed. In addition, the histopathology and immunohistochemistry of the femur and tibia AC or SM were performed.

Results: The surgically-induced OA signs in rats were significantly inhibited by 28 days of continuous treatment of PCP, EC and AR single formulas, and PCP with EC:AR mixed formulas. Especially, PCP with EC:AR 4:1, 2:1 and 1:1 mixed formula treatment constantly showed significantly more favorable inhibitory activities, as compared with those of single formula of PCP, EC and AR treated rats.

Conclusion: PCP and EC:AR 4:1 mixed formula showed similar OA refinement effects through potent anti-inflammatory pathways as compared with those of diclofenac treatment, and showed additional chondrocyte proliferating effects on the both femur and tibia AC.

Key Words : Mixed formulation, Selections of the fittest mixed formula, Dried pomegranate concentrate powders, Eucommiae Cortex, Achyranthis Radix, Surgically-induced osteoarthritic rats.

\footnotetext{
- Received : 22 July 2017 - Revised : 25 November 2017 Accepted : 1 December 2017

- Correspondence to: Young-Joon Lee

Department of Preventive medicine, College of Korean Medicine, Daegu Haany University

1 Haanydaero, Gyeongsan, Gyeongsangbuk-Do, 38610, Republic of Korea

Tel : +82-53-819-1296, Fax : +82-53-819-1576, E-mail : gksxntk@dhu.ac.kr

- Correspondence to : Ki-Moon Park

Department of Foodscience and biotechnology, Sungkyunkwan University

2066 Seoburo, Jangan-gu, Suwon, Gyeonggi-do, 16419, Republic of Korea.

Tel : +82-31-290-7806, E-mail : Pkm1001@skku.edu
} 


\section{Introduction}

Osteoarthritis (OA) is one of the most prevalent articular diseases in elderly adults ${ }^{1)}$, and clinical syndromes such as joint pain result in functional limitations that reduce quality of life $^{2)}$. OA is a degenerative inflammatory process of articular cartilage (AC) that includes changes in structure and in articulation function ${ }^{3,4)}$. The extracellular matrix (ECM) of $\mathrm{AC}$ is composed mainly of collagen and proteoglycans (PGs), aggrecan, and SOX9 ${ }^{5,6}$. Tissue destruction and hypocellularity follow once AC components are lost, leading to eventual loss of joint function $^{7)}$. In particular, proinflammatory cytokines stimulate cartilage resorption and inhibit synthesis of new matrix components in $\mathrm{AC}^{8,9)}$. Additionally, cytokines increase prostaglandin $\mathrm{E}_{2}\left(\mathrm{PGE}_{2}\right)$ levels and nitric oxide release from chondrocytes ${ }^{10,11)}$, which have both been implicated in turnover of the cartilage matrix ${ }^{12,13)}$. However, the etiopathology of OA is not fully understood ${ }^{14)}$.

Although use of nonsteroidal anti-inflammatory drugs during clinical treatment of $\mathrm{OA}$ can be deleterious, they suppress the synthesis of $\mathrm{PGs}^{15}$. Efforts have been made to develop and identify agents that preserve cartilage ${ }^{5,6,16}$. Natural sources and formulations have achieved potent anti-arthritic effects, and pomegranate products have traditionally been used to treat various diseases ${ }^{17)}$. Pomegranate consists of crude fiber, pectin, sugars, and several tannins ${ }^{18)}$. Notably, pomegranate seed oil and juice contain abundant flavonoids and anthocyanidins ${ }^{19,20)}$. Furthermore, accumulating evidence indicates that pomegranate has powerful and favorable protective effects in chondrocytes through potent antioxidant and anti-inflammatory effects ${ }^{21-24)}$. Eucommiae Cortex (EC), which is the dried stem bark of Eucommia ulmoides Oliver (Eucommiaceae), has been used as a traditional medicine in Korea for its antihypertensive, anti-inflammatory, antiviral, kidney-invigorating, and hepatoprotective activities, which it achieves without side effects ${ }^{25-27)}$. In particular, as a component of mixed herbal formulations, EC has been reported to have anti-arthritic effects ${ }^{28,29)}$. Achyranthis Radix (AR), the dried roots of Achyranthes bidentata Blume, is an important traditional Korean medicine that is used extensively by medical practitioners to treat osteodynia of the lumbar region and knees, spasms, and flaccidity of the limbs ${ }^{30}$. In particular, the anti-arthritic effects of AR have also been well documented in in vivo and in vitro studies ${ }^{31,32)}$.

We hypothesized that a mixed formulation of pomegranate concentrated powder (PCP) and appropriate proportions of $\mathrm{EC}$ and $\mathrm{AR}$ would enhance its protective effects against $\mathrm{OA}$ because, through their diverse ingredients, mixtures of medicinal agents can elevate biological activities that combat many diseases. Thus, this study aimed to select or observe the optimal ranges showing obvious synergic anti-OA potential of mixtures of PCP, EC, and $\mathrm{AR}$ and their effects on surgically induced OA in rats were examined.

\section{Materials and Methods}

\section{Animals and induction of OA: transection of the anterior cruciate ligament and partial medial meniscectomy}

In total, 150 healthy male specific-pathogen-free/ VAF outbred-Crl: CD1 rats were used after a 7-day acclimation. The animals were allocated five to a polycarbonate cage in a temperature- $\left(20-25^{\circ} \mathrm{C}\right)$ and humidity- (45-55\%) controlled room. The light: dark cycle was $12 \mathrm{~h}: 12 \mathrm{~h}$, and feed (Samyang, Seoul, Korea) and tap water were supplied ad libitum. Six days after the OA operation, 10 rats in each group were selected based on body weight and knee thickness deviations. Fifteen groups of 10 rats/group were killed for analyses.

The rats were anesthetized with $2-3 \%$ isoflurane in a mixture of $70 \% \mathrm{~N}_{2} \mathrm{O}$ and $28.5 \% \mathrm{O}_{2}$ and were 
maintained with $1-1.5 \%$ isoflurane in a mixture of $70 \% \mathrm{~N}_{2} \mathrm{O}$ and $28.5 \% \mathrm{O}_{2}$ using a rodent inhalation anesthesia apparatus and a rodent ventilator. The OA treatment group underwent open surgery involving transection of the anterior cruciate ligament and a partial medial meniscectomy via an incision on the medial aspect of the joint capsule, anterior to the medial collateral ligament. The incision was closed in two layers. The joint capsule was sutured independently from peripheral tissues using dissolvable 5-0 Vicryl, and the skin was closed with interrupted silk sutures. This treatment was used to induce OA pathogenesis and is referred to as the operation-induced side. Conversely, the right (non-operated, intact side) knee joint was used for the contralateral treatment. The second group of rats underwent a sham operation in which a similar incision was made in the joint capsule, but the anterior cruciate ligament was not transected and according to our established methods no partial medial meniscectomy was performed ${ }^{33-36)}$.

All laboratory animals were treated according to the national regulations of the usage and welfare of laboratory animals, and approved by the Institutional Animal Care and Use Committee in Daegu Haany University (Gyeongsan, Gyeongbuk, Korea) prior to animal experiment [Approval No DHU2014-052].

Experimental groups (Fifteen groups, ten rats in each group were finally sacrificed)

- Vehicle control: Sham-operated and distilled water orally administered rats

- OA control: OA-surgery and distilled water orally administered rats

- Diclofenac: OA-surgery and diclofenac sodium 2 $\mathrm{mg} / \mathrm{kg}$ subcutaneously treated rats

- PCP: OA-surgery and PCP single formula 200 $\mathrm{mg} / \mathrm{kg}$ orally administered rats

- EC: OA-surgery and EC single formula $200 \mathrm{mg} / \mathrm{kg}$ orally administered rats

- AR: OA-surgery and AR single formula 200 $\mathrm{mg} / \mathrm{kg}$ orally administered rats
- Nine types of PCP with EC:AR mixed formula $200 \mathrm{mg} / \mathrm{kg}$ orally administrated OA rats

- 1:1 = PCP $100 \mathrm{mg}$ with EC:AR 1:1 (50:50 $\mathrm{mg}: \mathrm{mg}$ ) mixed formula administered OA rats

- 1:2 = PCP $100 \mathrm{mg}$ with EC:AR 1:2 (33:67 $\mathrm{mg}: \mathrm{mg}$ ) mixed formula administered OA rats

- 1:4 = PCP $100 \mathrm{mg}$ with EC:AR 1:4 (20:80 mg:mg) mixed formula administered OA rats

- 1:6 = PCP $100 \mathrm{mg}$ with EC:AR 1:6 (14:86 mg:mg) mixed formula administered OA rats

- 1:8 = PCP $100 \mathrm{mg}$ with EC:AR 1:8 (11:89 mg:mg) mixed formula administered OA rats

- 2:1 = PCP $100 \mathrm{mg}$ with EC:AR 2:1 (67:33 mg:mg) mixed formula administered OA rats - 4:1 = PCP $100 \mathrm{mg}$ with EC:AR 4:1 (80:20 mg:mg) mixed formula administered OA rats

- 6:1 = PCP $100 \mathrm{mg}$ with EC:AR 6:1 (86:14 $\mathrm{mg}: \mathrm{mg}$ ) mixed formula administered OA rats

- 8:1 = PCP $100 \mathrm{mg}$ with EC:AR 8:1 (89:11 $\mathrm{mg}: \mathrm{mg}$ ) mixed formula administered OA rats

\section{Preparations and administration of test substances}

PCP (ASYA Meyve Suyu ve Gıda San. A.Ş., Ankara, Turkey) as pink colored powders contains $1.15 \mathrm{mg} / \mathrm{g}$ ellagic acid as an active ingredient, EC as deep brown colored powders contains $1.62 \mathrm{mg} / \mathrm{g}$ pinoresinol diglucoside, $\mathrm{AR}$ as brown colored powders contained $0.25 \mathrm{mg} / \mathrm{g}$ ecdysterone, were prepared and supplied by Health Love Ltd. (Anyang, Korea). Briefly, aliquots of the dried EC and AR were boiled at $121^{\circ} \mathrm{C}$ during $7 \mathrm{~h}$, and the resulting liquid was filtered. The filtrate was concentrated, and then spray dried to obtain a dried powder. All test materials were stored at $4^{\circ} \mathrm{C}$ to protect them from light and moisture. A $200-\mathrm{mg} / \mathrm{kg}$ dose was selected as the total dose of a mixed formula consisting of PCP with an EC:AR ratio based on the highest possible clinical dose in humans. The single herbal extracts, such as PCP, EC, and AR, were 
administered at $200 \mathrm{mg} / \mathrm{kg}$ to compare their effects directly with any synergistic effects produced by the mixed formulas. The nine mixed herbal preparations $(200 \mathrm{mg} / \mathrm{kg}$; PCP with EC:AR = 1:1, 1:2, 1:4, 1:6, $1: 8,2: 1,4: 1,6: 1$, and 8:1) and three single formulas dissolved in distilled water were administered orally by gastric gavage once daily for 28 days beginning at 1 week after $\mathrm{OA}$ surgery at a rate of $5 \mathrm{ml} / \mathrm{kg}$. Diclofenac $(2 \mathrm{mg}$ ) was dissolved in $5 \mathrm{ml}$ sterile saline and subcutaneously injected under the dorsal back skin at a rate of $5 \mathrm{ml} / \mathrm{kg}(2 \mathrm{mg} / \mathrm{kg})$ once daily for 28 days beginning 7 days after OA surgery, as in our previous study ${ }^{33-36}$. Equal volumes of vehicle (distilled water) were administered orally to sham and OA control rats. Half quantities of the mixed formulations were prepared as $100 \mathrm{mg}$ PCP in a total of $200 \mathrm{mg}$ in $5 \mathrm{ml}$ distilled water based on our in vitro data (not published), and the following amounts of EC and AR were added: 1:1, 1:2, 1:4, 1:6, 1:8, 2:1, 4:1, 6:1, and (mg: mg) $8: 1$ or 50:50, 33:67, 20:80, 14:86, 11:89, 67:33, 80:20, 86:14, and 89:11, respectively. Each single formula of PCP, EC, and AR was prepared by directly dissolving $200 \mathrm{mg}$ in 5 $\mathrm{ml}$ distilled water.

\section{Body weight measurements}

Changes in body weight were measured at least once weekly beginning 1 day before the $\mathrm{OA}$ operation until death ( $24 \mathrm{~h}$ after the last (day 28) administration) using an automatic electronic balance. To reduce any effect of feeding, all experimental animals were fasted overnight for about $18 \mathrm{~h}$ before the OA surgery, at the initial administration, and at termination.

\section{Knee thickness measurements}

The thickness of individual OA-operated hind knees (left side) was measured using an electronic digital caliper (Mytutoyo, Tokyo, Japan) at 6 days after the OA operation, on the day of initial administration, and at 1, 7, 14, 21, 27, and 28 days after treatment. Additionally, according to our established methods ${ }^{33-36}$, knee thickness was measured after exposing the joint capsule and after sacrifice to reduce any differences resulting from surrounding tissues.

\section{Measurement of maximum extension angle of each knee}

The OA-operated knees of all animals were dissected from the coxofemoral to the ankle region, leaving the articular capsule intact. After dissection, the maximum extension angle of each knee was measured according to previous methods ${ }^{33-37)} ; 0^{\circ}$ corresponded to the maximum possible extension. All operations and measurements of extension were performed by the same veterinarian to minimize bias.

\section{Preparation of the femur and tibia AC with SM tissue homogenates}

After measuring the maximum extension angle of each knee, some parts of the femoral and tibial AC with SM tissue were separated individually, and tissue homogenates were prepared using a bead beater (Model TacoTMPre, GeneResearch Biotechnology Corp., Taichung, Taiwan), ultrasonic cell disruptor (Model KS-750, Madell Technology Corp., Ontario, CA, USA), and radioimmunoprecipitation (RIPA) assay buffer (Sigma-Aldrich, St. Louise, MO, USA). The supernatant was separated by centrifugation at $21,000 \mathrm{xg}$ and $4^{\circ} \mathrm{C}$ to measure $\mathrm{PGE}_{2}$ levels and 5-LPO, MMP-2, and MMP-9 activities.

\section{Detection of the $\mathrm{PGE}_{2}$ levels on the femoral and tibial $A C$ with $S M$}

The $\mathrm{PGE}_{2}$ contents in the prepared supernatants of femoral and tibial AC with SM tissue homogenates were separately measured using a commercial $\mathrm{PGE}_{2}$ assay kit (Cat No. KGE004B; R\&D Systems, Minneapolis, MN, USA) with a micro plate reader 
(Sunrise; Tecan, Männedorf, Switzerland) as $\mathrm{pg} / \mathrm{ml}$ levels, according to instructor's protocol, as reported previously ${ }^{16)}$.

\section{Assay of 5-LPO activity}

The 5-LPO activities in the prepared supernatants of femoral and tibial AC with SM tissue homogenates were separately measured using a commercial Lipoxygenase Inhibitor Screening Assay kit (Cat No. 760700; Cayman Chemical, Ann Arbor, MI, USA) with a micro plate reader as $\mu \mathrm{M} / \mathrm{min} / \mathrm{ml}$ of supernatant according to instructor's protocol, as reported previously ${ }^{16)}$.

\section{MMP inhibitory assays}

The MMP-2 and MMP-9 activities in the prepared supernatants of femoral and tibial AC with SM tissue homogenates were separately measured a commercial MMP ELISA kit (Cat No. MBS720217 for MMP-2 and Cat No. MBS722532 for MMP-9; Mybiosource, San Diego, CA, USA) with a micro plate reader at OD $560 \mathrm{~nm}$ as $\mathrm{ng} / \mathrm{ml}$ of supernatant according to instructor's protocol, as reported previously ${ }^{6}$, respectively.

\section{Realtime RT-PCR for ECM related chondrogenic gene mRNA expressions}

Collagen type II, SOX9 and aggrecan mRNA expressions in the prepared femoral and tibial $\mathrm{AC}$ and SM homogenates were detected by realtime reverse transcription-polymerase chain reaction (RT-PCR) analysis according to previously established methods ${ }^{38,39)}$. Briefly, RNA was extracted using Trizol reagent (Invitrogen, Carlsbad, CA, USA), according to previously established methods ${ }^{6,16}$. The RNA concentrations and quality were determined using a CFX96 $^{\mathrm{TM}}$ Real-Time System (Bio-Rad, Hercules, CA, USA). To remove contaminating DNA, samples were treated with recombinant DNase I (DNA-free; Ambion, Austin, TX, USA). RNA was reverse transcribed using the reagent High-Capacity cDNA Reverse Transcription Kit (Applied Biosystems, Foster City, CA, USA) according to the manufacturer's instructions. And also briefly, the cDNA strand first was synthesized from the total RNA and then the mixture of the primers and the cDNA products was amplified by PCR, and the conditions of PCR amplification were $58^{\circ} \mathrm{C}$ for $30 \mathrm{~min}, 94^{\circ} \mathrm{C}$ for $2 \mathrm{~min}$, 35 cycles of $94^{\circ} \mathrm{C}$ for $15 \mathrm{sec}, 60^{\circ} \mathrm{C}$ for $30 \mathrm{sec}, 68^{\circ} \mathrm{C}$ for $1 \mathrm{~min}$, and then $72^{\circ} \mathrm{C}$ for $5 \mathrm{~min}$. The analysis was carried out using an ABI Step One Plus Sequence Detection System (Applied Biosystems, Foster City, CA, USA), and expression levels were calculated relative to those of the vehicle control. The expression of $\beta$-actin mRNA was used as a control for tissue integrity in all samples. The sequences of the PCR oligonucleotide primers were as listed in Table 1.

\section{Bromodeoxyuridine (BrdU) uptake assay}

To assess the effects of the test substances on the proliferation of cells within the rat knee joint, proliferating cells were labeled by an intraperitoneal injection of $50 \mathrm{mg} / \mathrm{kg}$ BrdU (Sigma-Aldrich, St. Louise, MO, USA) at a rate of $2 \mathrm{ml} / \mathrm{kg}$, dissolved in saline, and the animals were killed $72 \mathrm{~h}$ later, as described previously ${ }^{35,40)}$. BrdU uptake was determined by immunohistochemistry using an anti-BrdU antibody for the femoral and tibial $\mathrm{AC}$ surface and SM tissue, as described previously $y^{33,34,36)}$.

\section{Histological process}

The knee joints were sampled with the joint capsules preserved, fixed in $10 \%$ neutral buffered formalin (NBF), and decalcified in decalcifying solution $[24.4 \%$ formic acid, and $0.5 \mathrm{~N}$ sodium hydroxide] for 5 days. Each knee joint was longitudinally trimmed, embedded in paraffin, sectioned (3 4 $\mu \mathrm{m})$ using a tungsten blade equipped with an automated polycut microtome (Model 
Table 1. Oligonucleotides for Realtime RT-PCR Used in This Study

\begin{tabular}{|c|c|c|c|}
\hline Target & $5^{\prime}-3^{\prime}$ & Sequence & $\begin{array}{l}\text { NCBI accession No. } \\
\text { (Molecular weights) }\end{array}$ \\
\hline \multirow{2}{*}{ Collagen type II } & Sense & GAGTGGAAGAGCGGAGACTACTG & \multirow{2}{*}{$\begin{array}{c}\text { NM_012929 } \\
(4538 \text { bp) }\end{array}$} \\
\hline & Antisense & CTCCATGTTGCAGAAGACTTTCA & \\
\hline \multirow{2}{*}{ SOX9 } & Sense & AGAGCGTTGCTCGGAACTGT & \multirow{2}{*}{$\begin{array}{l}\text { NM_080403 } \\
\text { (4032 bp) }\end{array}$} \\
\hline & Antisense & TCCTGGACCGAAACTGGTAAA & \\
\hline \multirow{2}{*}{ Aggrecan } & Sense & GATGTCCCCTGCAATTACCA & \multirow{2}{*}{$\begin{array}{l}\text { NM_022190 } \\
(6939 \text { bp })\end{array}$} \\
\hline & Antisense & TCTGTGCAAGTGATTCGAGG & \\
\hline \multirow{2}{*}{$\beta$-actin } & Sense & ATCGTGGGCCGCCCTAGGCA & \multirow{2}{*}{$\begin{array}{l}\text { NM_031144 } \\
\text { (1293 bp) }\end{array}$} \\
\hline & Antisense & TGGCCTTAGGGTTCAGAGGGG & \\
\hline
\end{tabular}

$\mathrm{NCBI}=$ National Center for Biotechnology Information; RT-PCR = reverse transcription polymerase chain reaction; SOX9 = SRY (sex determining region $\mathrm{Y})$-box 9

RM2255, Leica, Wetzlar, Germany), and stained with Sirius Red stain for cartilaginous tissues ${ }^{33,34,36)}$. The histological profiles of all samples were interpreted under a light microscope (Model Eclipse 80i, Nikkon, Tokyo, Japan) by an assessor blind to the group distribution.

\section{Immunohistochemistry}

$\mathrm{BrdU}^{35,40)}$ immunoreactivity was determined using a purified primary antibody with avidin-biotin complex $(\mathrm{ABC})$ reagents and a peroxidase substrate kit (Cat No. PK6200; Vector Labs, Burlingame, CA, USA) on prepared femoral and tibial AC and SM tissues using the apoptotic marker poly(ADP-ribose) polymerase $(\mathrm{PARP})^{41)}$, proinflammatory cytokine tumor necrosis factor (TNF)- $a$, and cyclooxygenase (COX)-2 ${ }^{42,43)}$. Briefly, endogenous peroxidase activity was blocked by a 30-min incubation with methanol and $0.3 \% \mathrm{H}_{2} \mathrm{O}_{2}$, and the non-specific binding of immunoglobulin was blocked with normal horse serum blocking solution for $1 \mathrm{~h}$ in a humid chamber after epitope retrieval using trypsin (Sigma-Aldrich, St. Louise, MO, USA) and $2 \mathrm{~N} \mathrm{HCl}$, as described previously ${ }^{33-36)}$, on the prepared unstained sections. Primary antisera were added overnight in a humidity chamber at $4^{\circ} \mathrm{C}$ and incubated with biotinylated universal secondary antibody and $\mathrm{ABC}$ reagents for $1 \mathrm{~h}$ at room temperature in the humidity chamber.
Finally, the sections were reacted with a peroxidase substrate kit for $3 \mathrm{~min}$ at room temperature.

\section{Histomorphometry}

The femoral and tibial AC injuries in the knees were evaluated and recorded using the Mankin scoring system and Safranin-O stain to observe the histopathology in more detail. The entire histological evaluation was performed by the same pathologist. Additionally, in accordance with our previously established method ${ }^{33-36}$, the thickness of the tibial and femoral $\mathrm{AC}(\mu \mathrm{m} /$ cartilage) and the epithelial lining of the SM tissue ( $\mu \mathrm{m} / \mathrm{knee}$ joint) and the number of inflammatory cells infiltrating the SM tissue (cells $/ \mathrm{mm}^{2}$ ) were measured in longitudinally trimmed samples using a computer-based automated image analyzer (iSolution FL ver 9.1, IMT $i$-solution Inc., Vancouver, Quebec, Canada). The histopathologist was blind to the group distribution during this analysis. Additionally, when cells were occupied by $>20 \%$ immunoreactivity, the density of each antibody for BrdU, PARP, TNF- $a$, and COX-2 was considered positive, and the number of immunoreactive cells was counted separately in each femoral and tibial AC with SM tissue using an automated digital image analyzer as cells $/ \mathrm{mm}^{2}$. One histological region of femoral and tibial AC with SM tissue in each rat (total 10 fields in each group) was 
Table 2. Body Weight Gains in Sham-operated or OA Rats

\begin{tabular}{|c|c|c|c|c|c|c|}
\hline \multirow[b]{2}{*}{ Groups } & \multicolumn{4}{|c|}{ Body weights $(\mathrm{g})$ at } & \multicolumn{2}{|c|}{ Body weight gains $(\mathrm{g})$} \\
\hline & $\begin{array}{l}\mathrm{OA} \\
{[\mathrm{A}]^{*}}\end{array}$ & $\begin{array}{c}6 \text { days after } \\
\text { OA }\end{array}$ & $\begin{array}{l}\text { First treatment } \\
{[\mathrm{B}]^{*}}\end{array}$ & $\begin{array}{l}\text { Sacrifice } \\
{[\mathrm{C}]^{*}}\end{array}$ & $\begin{array}{c}\text { OA recovery } \\
{[\mathrm{B}-\mathrm{A}]}\end{array}$ & $\begin{array}{l}\text { Treatment } \\
\text { [C-B] }\end{array}$ \\
\hline \multicolumn{7}{|l|}{ Controls } \\
\hline Sham & $206.00 \pm 11.51$ & $264.60 \pm 19.48$ & $249.00 \pm 18.78$ & $396.80 \pm 18.32$ & $43.00 \pm 8.83$ & $147.80 \pm 17.70$ \\
\hline $\mathrm{OA}$ & $205.60 \pm 7.76$ & $252.20 \pm 8.59$ & $238.30 \pm 9.43$ & $373.50 \pm 21.79$ & $32.70 \pm 7.26^{\mathrm{a}}$ & $135.20 \pm 13.73$ \\
\hline Diclofenac & $204.90 \pm 12.14$ & $251.50 \pm 20.59^{\mathrm{b}}$ & $236.20 \pm 20.39^{b}$ & $385.00 \pm 52.94$ & $31.30 \pm 13.36^{\mathrm{a}}$ & $148.80 \pm 34.21$ \\
\hline \multicolumn{7}{|l|}{ Single formula } \\
\hline PCP & $209.80 \pm 8.15$ & $255.00 \pm 15.57$ & $240.60 \pm 14.58$ & $386.00 \pm 34.55$ & $30.80 \pm 8.84^{\mathrm{a}}$ & $145.40 \pm 31.37$ \\
\hline $\mathrm{EC}$ & $206.20 \pm 8.66$ & $254.40 \pm 13.41$ & $241.10 \pm 13.16$ & $375.50 \pm 42.62$ & $34.90 \pm 6.45^{\mathrm{b}}$ & $134.40 \pm 34.58$ \\
\hline $\mathrm{AR}$ & $205.40 \pm 11.30$ & $253.10 \pm 16.70$ & $240.60 \pm 16.87$ & $381.00 \pm 39.11$ & $35.20 \pm 7.52^{b}$ & $140.40 \pm 23.52$ \\
\hline \multicolumn{7}{|c|}{ Mixed formula - PCP and EC:AR } \\
\hline $1: 1$ & $210.60 \pm 8.25$ & $261.90 \pm 12.61$ & $246.70 \pm 12.05$ & $387.50 \pm 37.30$ & $36.10 \pm 4.41^{\mathrm{b}}$ & $140.80 \pm 29.98$ \\
\hline $1: 2$ & $200.70 \pm 9.87$ & $246.50 \pm 14.14^{\mathrm{a}}$ & $231.90 \pm 14.08^{\mathrm{a}}$ & $371.10 \pm 42.66^{\mathrm{b}}$ & $31.20 \pm 8.56^{\mathrm{a}}$ & $139.20 \pm 30.48$ \\
\hline $1: 4$ & $206.20 \pm 8.36$ & $253.40 \pm 13.22$ & $239.10 \pm 14.65$ & $392.60 \pm 31.59$ & $32.90 \pm 7.22^{\mathrm{a}}$ & $153.50 \pm 19.97^{\mathrm{c}}$ \\
\hline $1: 6$ & $204.50 \pm 9.28$ & $254.60 \pm 12.96$ & $238.70 \pm 10.85$ & $381.10 \pm 23.39$ & $34.20 \pm 4.08^{b}$ & $142.40 \pm 19.35$ \\
\hline $1: 8$ & $207.70 \pm 9.78$ & $258.10 \pm 18.47$ & $243.40 \pm 15.61$ & $395.50 \pm 48.19$ & $35.70 \pm 8.69^{\mathrm{a}}$ & $152.10 \pm 36.37$ \\
\hline $2: 1$ & $205.30 \pm 5.44$ & $253.40 \pm 8.57$ & $238.90 \pm 7.68$ & $376.10 \pm 13.55$ & $33.60 \pm 6.40^{\mathrm{b}}$ & $137.20 \pm 10.99$ \\
\hline $4: 1$ & $207.30 \pm 8.41$ & $256.00 \pm 8.63$ & $242.00 \pm 7.39$ & $379.80 \pm 32.77$ & $34.70 \pm 4.90^{b}$ & $137.80 \pm 26.73$ \\
\hline $6: 1$ & $205.60 \pm 10.57$ & $253.50 \pm 14.14$ & $237.80 \pm 14.20$ & $373.40 \pm 32.92$ & $32.20 \pm 7.57^{\mathrm{a}}$ & $135.60 \pm 27.03$ \\
\hline $8: 1$ & $204.20 \pm 5.20$ & $252.10 \pm 12.85$ & $237.30 \pm 12.22$ & $375.30 \pm 26.30$ & $33.10 \pm 7.92^{\mathrm{a}}$ & $138.00 \pm 16.38$ \\
\hline
\end{tabular}

Values are expressed mean \pm SD of 10 rats, g. AR = Aqueous extracts of Achyranthis Radix; OA = Osteoarthritis; EC $=$ Aqueous extracts of Eucommiae Cortex, PCP $=$ Pomegranate Concentration Powder. ${ }^{*}$ All animals were overnight fasted. ${ }^{a} p<0.01$ and ${ }^{b} p<$ 0.05 as compared with sham control; ${ }^{c} p<0.05$ as compared with OA control.

considered separately for further analysis.

\section{Statistical analyses}

All values are presented as the mean \pm standard deviation of the 10 rats in this experiment. Multiple comparison tests were conducted for the groups receiving different doses. The homogeneity of variance was examined using the Levene test. When the Levene test indicated no significant deviations from the homogeneity of the variance, the data were analyzed by one-way analysis of variance followed by the least-significant difference multi-comparison test to identify the significantly different member of a pair. The non-parametric Kruskal-Wallis $\mathrm{H}$ test was performed on data with a heterogeneous variance. When a significant difference was detected by the Kruskal-Wallis $\mathrm{H}$ test, the Mann-Whitney U-test with Bonferroni's correction was used to determine the specific pairs that differed. Statistical analyses were conducted using SPSS for Windows. Differences were considered significant at $p<0.05$.

\section{Results}

\section{Effects of PCP, EC, and the AR single formulas and nine PCP and EC:AR mixtures on body weight gain after OA surgery}

No significant changes in body weight were observed in the OA control rats during the 28 days of administration compared with sham control rats. However, significant decreases $(p<0.01)$ in body weight were demonstrated in OA control rats compared with the sham control rats during the 7 days of recovery. No changes in body weight were detected during the recovery and administration periods in the single-formula- or the nine PCP and EC:AR mixture-treated rats compared with OA control rats, except for significantly $(p<0.05)$ 
increased body weight gain during the 28 days of administration in the PCP and EC:AR 1:4 mixed -formula-treated rats compared with the $\mathrm{OA}$ control rats (Table 2).

\section{Changes on the knee thicknesses}

Knee thickness increased significantly $(p<0.01)$ in OA control rats compared with knee thickness in sham control rats beginning at 6 days after OA was induced. Significant decreases $(p<0.01$ or $p<0.05)$ in knee thickness were observed in the diclofenac-, AR single formula, PCP, and the EC:AR 1:2, 1:8, 2:1, and 4:1 mixed-formula-treated rats beginning at 1 day after the initial administration compared with values in the OA control rats. At 7 days after the initial administration in the PCP and EC single formula, PCP, and EC:AR 1:1, 1:4, 1:6, and 8:1 mixed formula-treated rats, and at 14 days after initial administration in the PCP and EC:AR 6:1 mixed formula-treated rats knee thickness was decreased compared with the OA control rats. In particular, the PCP and the EC:AR 4:1, 2:1, 1:1, 1:2, and 1:4 mixed formulas resulted in significant decreases $(p<0.01$ or $p<0.05)$ in knee thickness compared with the single formula (Figure 1).

\section{Effects on the knee thicknesses after capsule exposure}

The thickness of capsule-exposed knees increased significantly $(p<0.01)$ in OA control rats compared with the thickness in sham control rats, whereas knee thickness decreased significantly $(p<0.01$ or $p<0.05)$ after capsule exposure in all test-substance -treated rats, including the PCP single-formula -treated OA rats, compared with knee thickness in the OA control rats. In particular, the PCP and EC:AR 4:1, 2:1, 1:1, 1:2, and 1:4 mixed formulas caused significant decreases $(p<0.01$ or $p<0.05)$ in capsule-exposed knee thickness compared with each single formula (in that order) (Figure 2).

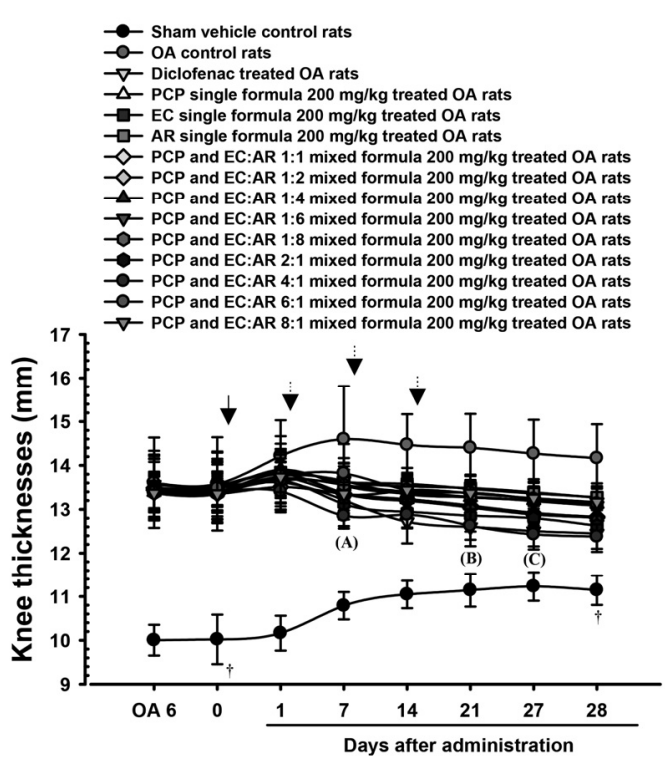

Fig. 1. Knee thickness changes in sham-operated or OA Rats. PCP and EC:AR 2:1 and 4:1 mixed formula treated rats showed significant $(p<0.01$ or $p<0.05)$ decreases of knee thicknesses from 7 days after initial administration as compared with each of PCP, $E C$ and $A R$ single formula treated rats (A), from 21 days after initial administration in PCP and EC:AR 1:1 and 1:4mixed formula treated rats (B), and from 27 days after initial administration in PCP and EC:AR 1:2 mixed formula treated rats as compared with each of PCP, EC and AR single formula treated rats $(C)$, respectively. Values are expressed mean \pm S.D. of 10 rats, $\mathrm{mm}$. Actual compositions of mixed formula - PCP and EC:AR and group identifications were listed in Table 1 and 2; AR = Aqueous extracts of Achyranthis Radix; $\mathrm{OA}=$ Osteoarthritis; $\mathrm{EC}=$ Aqueous extracts of Eucommiae Cortex; PCP = Pomegranate Concentration Powder. OA 6 means at 6 days after OA operation; 0 means at start of administration, at 7 days after OA operation; 28 means 28 days after initiation of administration, at sacrifice. All animals were overnight fasted before first administration and sacrifice, respectively $(\dagger)$.

\section{Effects on the knee maximum extension angles}

The maximum knee extension angle increased significantly $(p<0.01)$ in $\mathrm{OA}$ control rats compared with that in sham control rats, whereas the maximum extension angle of the knee decreased significantly in 
all test-substance-treated rats, including the EC single-formula-treated $\mathrm{OA}$ rats, compared with that in OA control rats. In particular, the PCP and EC:AR 4:1, 2:1, and 1:1 mixed formulas induced significant decreases $(p<0.01)$ in maximum knee extension angles compared with each single formula (in that order) (Figure 3).

5. Changes in $\mathrm{PGE}_{2}$ levels and 5-LPO and MMP activities in femoral and tibial $A C$

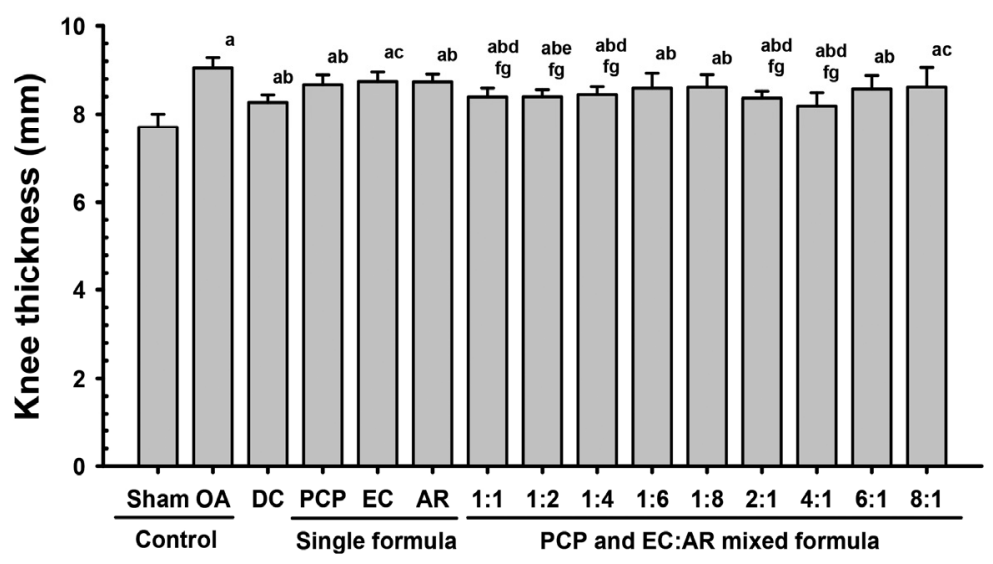

Fig. 2. Knee thickness after capsule exposure in sham-operated or OA Rats. Values are expressed mean \pm S.D. of 10 rats, $\mathrm{mm} . \mathrm{AR}=$ Aqueous extracts of Achyranthis Radix, DC = Diclofenac; $\mathrm{OA}=$ Osteoarthritis; $\mathrm{EC}=$ Aqueous extracts of Eucommiae Cortex, PCP = Pomegranate Concentration Powder. ${ }^{a} p<0.01$ as compared with sham control; ${ }^{b} p<0.01$ and ${ }^{\mathrm{C}} p<0.05$ as compared with OA control; ${ }^{\mathrm{d}} p<0.01$ and ${ }^{\mathrm{e}} p<0.05$ as compared with PCP single formula; ${ }^{\dagger} p<$ 0.01 as compared with EC single formula; ${ }^{9} p<0.01$ as compared with AR single formula.

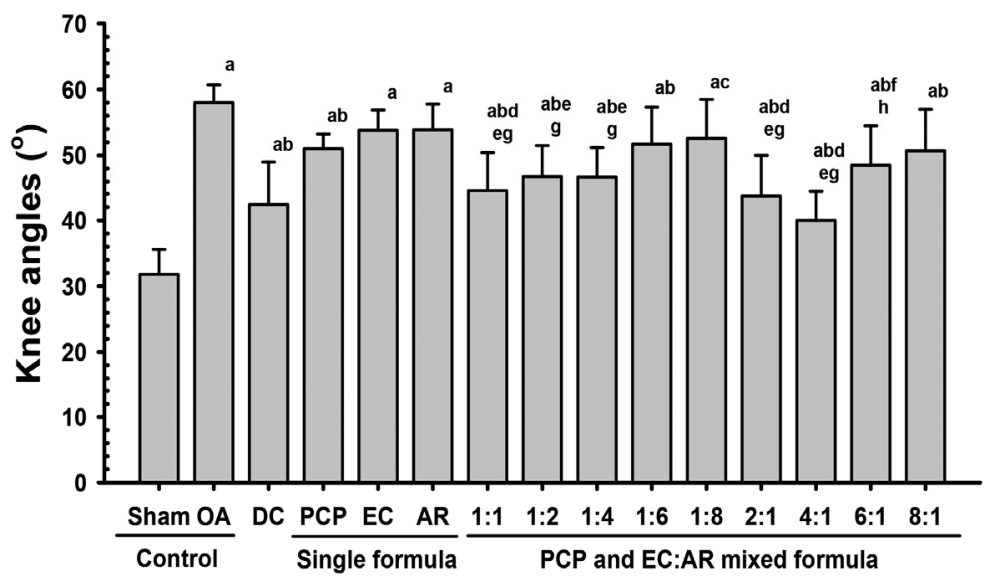

Fig. 3. Knee maximum extension angles in sham-operated or OA Rats. Values are expressed mean \pm S.D. of 10 rats, degrees $\left({ }^{\circ}\right)$. AR $=$ Aqueous extracts of Achyranthis Radix, $\mathrm{OA}=$ Osteoarthritis; $\mathrm{EC}=$ Aqueous extracts of Eucommiae Cortex, $\mathrm{PCP}=$ Pomegranate Concentration Powder. ${ }^{\mathrm{a}} p<0.01$ as compared with sham control; ${ }^{\mathrm{b}} p<0.01$ and ${ }^{c} p<0.05$ as compared with OA control; ${ }^{d} p<0.01$ as compared with PCP single formula; ${ }^{\mathrm{e}} p<0.01$ and ${ }^{\dagger} p$ $<0.05$ as compared with EC single formula; ${ }^{g} p<0.01$ and ${ }^{h} p<0.05$ as compared with AR single formula. 
(434) Journal of Korean Medicine 2017;38(4)

Table 3. Femoral and Tibial $A C$ with $S M \mathrm{PGE}_{2}$ Contents in Sham-Operated or OA Rats

\begin{tabular}{|c|c|c|c|}
\hline \multirow[b]{2}{*}{ Groups } & \multicolumn{3}{|c|}{$\mathrm{PGE}_{2}$ levels } \\
\hline & Femoral AC & Tibial AC & SM \\
\hline \multicolumn{4}{|l|}{ Controls } \\
\hline Sham & $36.45 \pm 11.08$ & $36.16 \pm 10.91$ & $35.99 \pm 10.93$ \\
\hline $\mathrm{OA}$ & $104.36 \pm 22.82^{\mathrm{a}}$ & $106.89 \pm 19.53^{\mathrm{a}}$ & $172.09 \pm 27.41^{\mathrm{a}}$ \\
\hline Diclofenac & $50.56 \pm 14.05^{\mathrm{bc}}$ & $47.16 \pm 7.01$ bc & $60.79 \pm 13.63$ ac \\
\hline \multicolumn{4}{|l|}{ Single formula } \\
\hline PCP & $78.62 \pm 7.61$ ac & $76.58 \pm 10.37^{\mathrm{ac}}$ & $124.97 \pm 22.35^{\mathrm{ac}}$ \\
\hline $\mathrm{EC}$ & $80.06 \pm 10.88^{\text {ac }}$ & $79.33 \pm 11.99$ ac & $131.98 \pm 16.82{ }^{\mathrm{ac}}$ \\
\hline $\mathrm{AR}$ & $81.82 \pm 8.95^{\mathrm{ac}}$ & $79.77 \pm 10.47$ ac & $130.89 \pm 20.34^{\mathrm{ac}}$ \\
\hline \multicolumn{4}{|c|}{ Mixed formula - PCP and EC:AR } \\
\hline $1: 1$ & $61.37 \pm 8.26^{\text {acegi }}$ & $62.49 \pm 6.822^{\text {acegi }}$ & $96.16 \pm 13.99$ acegi \\
\hline $1: 2$ & $63.65 \pm 6.84$ acegi & $63.80 \pm 10.15$ acfgi & $102.46 \pm 14.71$ acfgi \\
\hline $1: 4$ & $67.19 \pm 9.74$ acegi & $66.47 \pm 6.10$ acfhj & $104.30 \pm 13.98$ acfgi \\
\hline $1: 6$ & $80.84 \pm 11.91$ ac & $73.10 \pm 12.28{ }^{\mathrm{ac}}$ & $125.13 \pm 17.98^{\text {ac }}$ \\
\hline $1: 8$ & $81.20 \pm 11.13^{\mathrm{ad}}$ & $77.54 \pm 13.37^{\mathrm{ac}}$ & $129.27 \pm 18.93$ ac \\
\hline $2: 1$ & $60.13 \pm 10.93^{\text {acegi }}$ & $61.30 \pm 13.81$ acfgi & $87.91 \pm 20.71$ acegi \\
\hline $4: 1$ & $53.10 \pm 11.14$ acegi & $52.33 \pm 9.16^{\text {acegi }}$ & $74.87 \pm 18.72$ acegi \\
\hline $6: 1$ & $70.36 \pm 16.31$ ac & $71.76 \pm 13.35$ ac & $119.00 \pm 25.14^{\mathrm{ac}}$ \\
\hline $8: 1$ & $73.21 \pm 14.69^{\text {ac }}$ & $72.44 \pm 14.19^{\mathrm{ac}}$ & $124.62 \pm 33.30^{\mathrm{ac}}$ \\
\hline
\end{tabular}

Values are expressed mean $\pm \mathrm{SD}$ of 10 rats, $\mathrm{pg} / \mathrm{ml} . \mathrm{AR}=$ Aqueous extracts of Achyranthis Radix, OA = Osteoarthritis; $\mathrm{EC}=\mathrm{Aqueous}$ extracts of Eucommiae Cortex, $\mathrm{PCP}=$ Pomegranate Concentration Powder; $\mathrm{AC}=$ Articular cartilage; $\mathrm{SM}=$ Synovial membrane; $\mathrm{PGE}_{2}=$ Prostaglandin $\mathrm{E}_{2 .}{ }^{\mathrm{a}} p<0.01$ and ${ }^{\mathrm{b}} p<0.05$ as compared with sham control; ${ }^{c} p<0.01$ and ${ }^{\mathrm{d}} p<0.05$ as compared with $0 \mathrm{~A}$ control; ${ }^{\mathrm{e}}$ $p<0.01$ and ${ }^{\dagger} p<0.05$ as compared with PCP single formula; ${ }^{9} p<0.01$ and ${ }^{h} p<0.05$ as compared with EC single formula; ${ }^{i} p<0.01$ and ${ }^{i} p<0.05$ as compared with AR single formula.

Table 4. Femoral and Tibial AC with SM 5-LPO Activities in Sham-Operated or OA Rats

\begin{tabular}{|c|c|c|c|}
\hline \multirow[b]{2}{*}{ Groups } & \multicolumn{3}{|c|}{ 5-LPO activity } \\
\hline & Femoral AC & Tibial AC & SM \\
\hline \multicolumn{4}{|l|}{ Controls } \\
\hline Sham & $0.10 \pm 0.05$ & $0.09 \pm 0.05$ & $0.18 \pm 0.14$ \\
\hline OA & $1.23 \pm 0.28^{\mathrm{a}}$ & $1.22 \pm 0.20^{\mathrm{a}}$ & $3.56 \pm 1.03^{\mathrm{a}}$ \\
\hline Diclofenac & $0.44 \pm 0.12^{\mathrm{ab}}$ & $0.42 \pm 0.15^{\mathrm{ab}}$ & $1.67 \pm 0.61 \mathrm{ab}$ \\
\hline \multicolumn{4}{|l|}{ Single formula } \\
\hline PCP & $0.83 \pm 0.12^{\mathrm{ab}}$ & $0.82 \pm 0.10^{\mathrm{ab}}$ & $2.25 \pm 0.37^{\mathrm{ab}}$ \\
\hline $\mathrm{EC}$ & $0.89 \pm 0.16^{\mathrm{ab}}$ & $0.88 \pm 0.09^{\mathrm{ab}}$ & $2.50 \pm 0.46^{\mathrm{ac}}$ \\
\hline $\mathrm{AR}$ & $0.89 \pm 0.18{ }^{a b}$ & $0.91 \pm 0.14^{\mathrm{ab}}$ & $2.56 \pm 0.36^{\mathrm{ac}}$ \\
\hline \multicolumn{4}{|c|}{ Mixed formula - PCP and EC:AR } \\
\hline $1: 1$ & $0.62 \pm 0.10^{\text {abdfh }}$ & $0.58 \pm 0.07$ abdfh & $1.75 \pm 0.40$ abefh \\
\hline $1: 2$ & $0.63 \pm 0.11$ abdfh & $0.63 \pm 0.12$ abdfh & $1.83 \pm 0.21$ abdfh \\
\hline $1: 4$ & $0.68 \pm 0.11$ abefi & $0.69 \pm 0.13$ abefh & $1.93 \pm 0.20$ abegh \\
\hline $1: 6$ & $0.82 \pm 0.14^{\mathrm{ab}}$ & $0.81 \pm 0.15^{\mathrm{ab}}$ & $2.17 \pm 0.51 \mathrm{ab}$ \\
\hline $1: 8$ & $0.83 \pm 0.18^{\mathrm{ab}}$ & $0.84 \pm 0.20$ ab & $2.28 \pm 0.44^{\mathrm{ab}}$ \\
\hline $2: 1$ & $0.54 \pm 0.10^{\text {abdfh }}$ & $0.53 \pm 0.10$ abdfh & $1.57 \pm 0.28$ \\
\hline $4: 1$ & $0.48 \pm 0.09$ abdfh & $0.49 \pm 0.14$ abdfh & $1.43 \pm 0.27$ abdfh \\
\hline $6: 1$ & $0.78 \pm 0.18^{\mathrm{ab}}$ & $0.85 \pm 0.20^{\mathrm{ab}}$ & $2.15 \pm 0.63^{\mathrm{ab}}$ \\
\hline $8: 1$ & $0.82 \pm 0.17^{\mathrm{ab}}$ & $0.87 \pm 0.20^{\mathrm{ab}}$ & $2.23 \pm 0.54^{\mathrm{ab}}$ \\
\hline
\end{tabular}

Values are expressed mean $\pm \mathrm{SD}$ of 10 rats, $\mu \mathrm{M} / \mathrm{min} / \mathrm{ml}$. AR = Aqueous extracts of Achyranthis Radix, OA = Osteoarthritis; EC = Aqueous extracts of Eucommiae Cortex, $\mathrm{PCP}=$ Pomegranate Concentration Powder; $\mathrm{AC}=$ Articular cartilage; $\mathrm{SM}=\mathrm{Synovial}$ membrane; LPO = Lipoxygenase. ${ }^{a} p<0.01$ as compared with sham control; ${ }^{b} p<0.01$ and ${ }^{c} p<0.05$ as compared with $0 A$ control; ${ }^{d} p<0.01$ and ${ }^{\mathrm{e}} p<0.05$ as compared with PCP single formula; ${ }^{\dagger} p<0.01$ and ${ }^{9} p<0.05$ as compared with EC single formula; ${ }^{\mathrm{h}} p<0.01$ and ${ }^{\mathrm{i}} p<0.05$ as compared with AR single formula. 


\section{with SM tissue}

Significant increases $(p<0.01)$ in $\mathrm{PGE}_{2}$ levels and 5-LPO, MMP-2, and MMP-9 activities were detected in the femoral and tibial AC with SM tissue of OA control rats compared with levels and activities in sham control rats. However, $\mathrm{PGE}_{2}$ levels and 5-LPO, MMP-2, and MMP-9 activities decreased significantly $(p<0.01$ or $p<0.05)$ in the femoral and tibial AC with SM tissue of all test-substance-treated rats compared with values in $\mathrm{OA}$ control rats. In particular, PCP and EC:AR 4:1, 2:1, 1:1, 1:2, and 1:4 mixed formulas induced significant decreases $(p<0.01$ or $p<0.05$ ) in $\mathrm{PGE}_{2}$ levels and 5-LPO activities (Table 3 and 4), and the PCP and EC:AR 4:1, 2:1, and 1:1 mixed formulas caused significant decreases $(p<0.01$ or $p<0.05)$ in MMP-2 and MMP-9 activities in femoral and tibial AC with SM tissue compared with each single formula (in that order) (Table 5 and 6).

\section{Effects on the ECM-related chondrogenic genes-collagen type II, SOX9, and aggrecan mRNA expression from femoral and tibial $A C$ with SM tissue}

Significant decreases $(p<0.01)$ in collagen type II mRNA expression were detected in the femoral and tibial AC with significant increases $(p<0.01)$ in the SM tissue of OA control rats compared with values in sham control rats (Table 7). However, SOX9 and aggrecan mRNA expression levels decreased significantly $(p<0.01)$ in the femoral and tibial AC with SM tissue of OA control rats compared with levels in sham control rats (Table 8 and 9). All test-substance treatments increased collagen type II mRNA expression significantly $(p<0.01$ or $p<0.05)$ in the femoral and tibial $\mathrm{AC}$ and decreased expression in the SM tissue. Rats given all test treatments showed significantly increased $(p<0.01)$ SOX9 and aggrecan mRNA expression levels in the femoral and tibial AC with SM tissue compared with levels in OA control rats. In particular, PCP and the
EC:AR 4:1, 2:1, 1:1, 1:2, and 1:4 mixed formulas induced significant increases $(p<0.01$ or $p<0.05)$ in collagen type II mRNA expression of femoral and tibial AC, but they also induced a decrease in the SM tissue. PCP and the EC:AR 4:1, 2:1, and 1:1 mixed formulas induced significant increases $(p<$ 0.01 or $p<0.05$ ) in SOX9 and aggrecan mRNA expression levels from femoral and tibial AC with SM tissue compared with each single formula (in that order).

\section{Effects on the BrdU-immunoreactivity of femoral and tibial AC with SM tissue}

Significant decreases $(p<0.01)$ in the numbers of femoral and tibial AC BrdU-immunopositive cells were detected in $\mathrm{OA}$ control rats, whereas the number of SM BrdU-immunolabeled cells increased significantly $(p<0.01)$ in OA control rats compared with numbers in sham control rats. However, the numbers of femoral and tibial AC BrdU -immunoreactive cells increased significantly $(p<0.01)$, whereas the numbers of SM BrdU -immunopositive cells decreased significantly $(p<0.01)$ in all test-substance-treated rats compared with numbers in OA control rats; the only exception was diclofenac-treated rats, in which the numbers of BrdU-immunoreactive cells detected in the femoral and tibial $\mathrm{AC}$ were similar to values in $\mathrm{OA}$ control rats. In particular, PCP and the EC:AR 4:1, 2:1, 1:1, and 1:2 mixed formulas resulted in significant increases $(p<0.01)$ in the numbers of $\operatorname{BrdU}$ -immunolabeled cells in the femoral and tibial AC, but they resulted in decreases in SM tissue compared with each single formula (in that order) (Figure 4, Table 10).

\section{Changes in femoral and tibial $A C$ Mankin scores}

OA control rats showed a marked increase in surface cartilage damage, decreased numbers of 
(436) Journal of Korean Medicine 2017;38(4)

Table 5. Femoral and Tibial AC with SM MMP-2 Activities in Sham-Operated or OA Rats

\begin{tabular}{|c|c|c|c|}
\hline \multirow[b]{2}{*}{ Groups } & \multicolumn{3}{|c|}{ MMP-2 activity } \\
\hline & Femoral AC & Tibial AC & SM \\
\hline \multicolumn{4}{|l|}{ Controls } \\
\hline Sham & $0.74 \pm 0.26$ & $0.63 \pm 0.22$ & $0.70 \pm 0.30$ \\
\hline OA & $3.14 \pm 1.05^{\mathrm{a}}$ & $2.74 \pm 0.63^{\mathrm{a}}$ & $3.80 \pm 0.66^{\mathrm{a}}$ \\
\hline Diclofenac & $2.12 \pm 0.32 \mathrm{ab}$ & $1.83 \pm 0.29$ ab & $1.86 \pm 0.44^{\mathrm{ab}}$ \\
\hline \multicolumn{4}{|l|}{ Single formula } \\
\hline PCP & $2.14 \pm 0.27^{\mathrm{ab}}$ & $1.94 \pm 0.23^{\mathrm{ab}}$ & $2.52 \pm 0.44$ ab \\
\hline $\mathrm{EC}$ & $2.24 \pm 0.25^{\mathrm{ab}}$ & $2.10 \pm 0.23^{\mathrm{ab}}$ & $2.94 \pm 0.588^{a b}$ \\
\hline $\mathrm{AR}$ & $2.23 \pm 0.30^{\text {ac }}$ & $2.13 \pm 0.21$ ab & $3.14 \pm 0.42^{\mathrm{ab}}$ \\
\hline \multicolumn{4}{|c|}{ Mixed formula - PCP and EC:AR } \\
\hline $1: 1$ & $1.67 \pm 0.42$ abefg & $1.56 \pm 0.33$ abefg & $1.99 \pm 0.25^{\text {abefg }}$ \\
\hline $1: 2$ & $1.85 \pm 0.20$ abefg & $1.65 \pm 0.15^{\text {abdfg }}$ & $2.03 \pm 0.30$ abefg \\
\hline $1: 4$ & $1.85 \pm 0.28$ abefh & $1.71 \pm 0.14^{\text {abefg }}$ & $2.12 \pm 0.19$ abef \\
\hline $1: 6$ & $2.08 \pm 0.38^{\mathrm{ab}}$ & $1.97 \pm 0.34^{\mathrm{ab}}$ & $2.74 \pm 0.77^{\mathrm{ab}}$ \\
\hline $1: 8$ & $2.18 \pm 0.42^{\mathrm{ab}}$ & $2.02 \pm 0.46^{\mathrm{ab}}$ & $2.85 \pm 0.74^{\mathrm{ab}}$ \\
\hline $2: 1$ & $1.50 \pm 0.35^{\text {abdfg }}$ & $1.48 \pm 0.29^{\text {abdfg }}$ & $1.79 \pm 0.35^{\text {abdfg }}$ \\
\hline $4: 1$ & $1.41 \pm 0.31$ abdfg & $1.28 \pm 0.17^{\text {abdfg }}$ & $1.62 \pm 0.30$ abdfg \\
\hline $6: 1$ & $2.06 \pm 0.36^{\mathrm{ab}}$ & $1.94 \pm 0.26^{\mathrm{ab}}$ & $2.77 \pm 0.56^{\mathrm{ab}}$ \\
\hline $8: 1$ & $2.11 \pm 0.36^{\mathrm{ab}}$ & $1.95 \pm 0.39^{\mathrm{ab}}$ & $2.78 \pm 0.63 \mathrm{ab}$ \\
\hline
\end{tabular}

Values are expressed mean $\pm \mathrm{SD}$ of 10 rats, $\mu \mathrm{g} / \mathrm{ml}$. AR = Aqueous extracts of Achyranthis Radix, OA = Osteoarthritis; EC = Aqueous extracts of Eucommiae CorteX, PCP = Pomegranate Concentration Powder; AC = Articular cartilage; SM = Synovial membrane; MMP = Matrix metalloproteinase. ${ }^{a} p<0.01$ as compared with sham control; ${ }^{b} p<0.01$ and ${ }^{c} p<0.05$ as compared with $0 A$ control; ${ }^{d} p<0.01$ and ${ }^{\mathrm{e}} p<0.05$ as compared with PCP single formula; ${ }^{\dagger} p<0.01$ as compared with EC single formula; ${ }^{9} p<0.01$ and ${ }^{h} p<0.05$ as compared with AR single formula.

Table 6. Femoral and Tibial AC with SM MMP-9 Activities in Sham-Operated or OA Rats

\begin{tabular}{|c|c|c|c|}
\hline \multirow[b]{2}{*}{ Groups } & \multicolumn{3}{|c|}{ MMP-9 activity } \\
\hline & Femoral $\mathrm{AC}$ & Tibial AC & SM \\
\hline \multicolumn{4}{|l|}{ Controls } \\
\hline Sham & $0.73 \pm 0.17$ & $0.60 \pm 0.18$ & $0.63 \pm 0.23$ \\
\hline $\mathrm{OA}$ & $2.12 \pm 0.44^{\mathrm{a}}$ & $2.05 \pm 0.22$ & $3.86 \pm 0.97^{\mathrm{a}}$ \\
\hline Diclofenac & $1.42 \pm 0.26^{\mathrm{ab}}$ & $1.48 \pm 0.22 \mathrm{ab}$ & $2.38 \pm 0.55^{\mathrm{ab}}$ \\
\hline \multicolumn{4}{|l|}{ Single formula } \\
\hline PCP & $1.66 \pm 0.15^{\mathrm{ab}}$ & $1.51 \pm 0.14^{\mathrm{ab}}$ & $2.73 \pm 0.45^{\mathrm{ab}}$ \\
\hline EC & $1.68 \pm 0.16^{\mathrm{ab}}$ & $1.60 \pm 0.19^{\mathrm{ab}}$ & $2.81 \pm 0.24$ ab \\
\hline $\mathrm{AR}$ & $1.70 \pm 0.19^{\mathrm{ab}}$ & $1.67 \pm 0.19$ ab & $2.82 \pm 0.22$ ab \\
\hline \multicolumn{4}{|c|}{ Mixed formula - PCP and EC:AR } \\
\hline $1: 1$ & $1.40 \pm 0.15$ abcef & $1.32 \pm 0.13$ abdef & $2.19 \pm 0.21$ abdef \\
\hline $1: 2$ & $1.47 \pm 0.13$ abdef & $1.34 \pm 0.13$ abef & $2.28 \pm 0.24$ abdef \\
\hline $1: 4$ & $1.48 \pm 0.12$ abdef & $1.37 \pm 0.11$ abef & $2.31 \pm 0.24$ abdef \\
\hline $1: 6$ & $1.64 \pm 0.19^{a b}$ & $1.55 \pm 0.20 \mathrm{ab}$ & $2.64 \pm 0.31 \mathrm{ab}$ \\
\hline $1: 8$ & $1.66 \pm 0.15^{\mathrm{ab}}$ & $1.56 \pm 0.17^{\mathrm{ab}}$ & $2.72 \pm 0.41 \mathrm{ab}$ \\
\hline $2: 1$ & $1.34 \pm 0.25$ abcef & $1.23 \pm 0.13$ abcef & $1.95 \pm 0.21$ abcef \\
\hline $4: 1$ & $1.19 \pm 0.44^{\text {abcef }}$ & $1.03 \pm 0.19$ abcef & $1.53 \pm 0.39$ abcef \\
\hline $6: 1$ & $1.60 \pm 0.15^{\mathrm{ab}}$ & $1.51 \pm 0.30^{\mathrm{ab}}$ & $2.58 \pm 0.58$ \\
\hline $8: 1$ & $1.61 \pm 0.18^{\mathrm{ab}}$ & $1.55 \pm 0.22^{\mathrm{ab}}$ & $2.58 \pm 0.30^{\mathrm{ab}}$ \\
\hline
\end{tabular}

Values are expressed mean $\pm \mathrm{SD}$ of 10 rats, $\mu \mathrm{g} / \mathrm{ml}$. AR $=$ Aqueous extracts of Achyranthis Radix, OA $=$ Osteoarthritis; EC $=$ Aqueous extracts of Eucommiae Cortex, PCP = Pomegranate Concentration Powder; $\mathrm{AC}=$ Articular cartilage; SM = Synovial membrane; MMP = Matrix metalloproteinase ${ }^{a} p<0.01$ as compared with sham control; ${ }^{b} p<0.01$ as compared with $0 A$ control; ${ }^{c} p<0.01$ and ${ }^{d} p<0.05$ as compared with PCP single formula; ${ }^{e} p<0.01$ as compared with EC single formula; ${ }^{\dagger} p<0.01$ as compared with AR single formula. 
Table 7. Femoral and Tibial AC with SM Collagen Type II mRNA Expressions in Sham-Operated or OA Rats

\begin{tabular}{|c|c|c|c|}
\hline \multirow[b]{2}{*}{ Groups } & \multicolumn{3}{|c|}{ Collagen type II mRNA expressions } \\
\hline & Femoral AC & Tibial AC & SM \\
\hline \multicolumn{4}{|l|}{ Controls } \\
\hline Sham & $1.05 \pm 0.16$ & $1.01 \pm 0.12$ & $1.01 \pm 0.21$ \\
\hline OA & $0.34 \pm 0.11^{\mathrm{a}}$ & $0.31 \pm 0.07^{\mathrm{a}}$ & $5.41 \pm 1.27^{\mathrm{a}}$ \\
\hline Diclofenac & $0.69 \pm 0.10^{\mathrm{ab}}$ & $0.64 \pm 0.11^{\mathrm{ab}}$ & $2.74 \pm 0.95^{\mathrm{ab}}$ \\
\hline \multicolumn{4}{|l|}{ Single formula } \\
\hline PCP & $0.51 \pm 0.10^{\mathrm{ab}}$ & $0.49 \pm 0.04^{\mathrm{ab}}$ & $3.73 \pm 0.35^{\mathrm{ab}}$ \\
\hline $\mathrm{EC}$ & $0.49 \pm 0.10^{\mathrm{ab}}$ & $0.44 \pm 0.07^{\mathrm{ab}}$ & $4.05 \pm 0.50$ ab \\
\hline $\mathrm{AR}$ & $0.46 \pm 0.06^{\text {ac }}$ & $0.40 \pm 0.06^{\mathrm{ab}}$ & $4.04 \pm 0.47^{\mathrm{ab}}$ \\
\hline \multicolumn{4}{|c|}{ Mixed formula - PCP and EC:AR } \\
\hline $1: 1$ & $0.62 \pm 0.06^{\text {abefh }}$ & $0.62 \pm 0.09$ abdfh & $2.79 \pm 0.54$ abdfh \\
\hline $1: 2$ & $0.61 \pm 0.07^{\text {abegh }}$ & $0.58 \pm 0.07^{\text {abdfh }}$ & $3.04 \pm 0.48^{\text {abdfg }}$ \\
\hline $1: 4$ & $0.61 \pm 0.08$ abefh & $0.56 \pm 0.05^{\text {abdfh }}$ & $3.12 \pm 0.48^{\text {abefh }}$ \\
\hline $1: 6$ & $0.52 \pm 0.10^{\mathrm{ab}}$ & $0.47 \pm 0.11^{\mathrm{ab}}$ & $3.87 \pm 1.00^{\mathrm{ac}}$ \\
\hline $1: 8$ & $0.49 \pm 0.11^{a b}$ & $0.46 \pm 0.09$ ab & $3.96 \pm 0.83^{\text {ab }}$ \\
\hline $2: 1$ & $0.66 \pm 0.10^{\text {abdfh }}$ & $0.66 \pm 0.11^{\text {abdfh }}$ & $2.35 \pm 0.61$ abdfh \\
\hline $4: 1$ & $0.71 \pm 0.11^{\text {abdfh }}$ & $0.70 \pm 0.14^{\text {abdfh }}$ & $1.98 \pm 0.51$ abdfh \\
\hline $6: 1$ & $0.52 \pm 0.12^{\mathrm{ab}}$ & $0.49 \pm 0.14^{\mathrm{ab}}$ & $3.88 \pm 0.85^{\mathrm{ab}}$ \\
\hline $8: 1$ & $0.50 \pm 0.08^{a b}$ & $0.44 \pm 0.10^{\mathrm{ab}}$ & $3.97 \pm 0.95^{\mathrm{ac}}$ \\
\hline
\end{tabular}

Values are expressed mean $\pm \mathrm{SD}$ of 10 rats, Relative to control $/ \beta$-actin. $\mathrm{AR}=$ Aqueous extracts of Achyranthis Radix, $\mathrm{OA}=$ Osteoarthritis; $\mathrm{EC}=$ Aqueous extracts of Eucommiae Cortex, $\mathrm{PCP}=$ Pomegranate Concentration Powder; $\mathrm{AC}=$ Articular cartilage; $\mathrm{SM}$ $=$ Synovial membrane ${ }^{a} p<0.01$ as compared with sham control; ${ }^{b} p<0.01$ and ${ }^{c} p<0.05$ as compared with $\mathrm{OA}$ control; ${ }^{\mathrm{d}} p<0.01$ and ${ }^{\mathrm{e}} p<0.05$ as compared with PCP single formula; ${ }^{\dagger} p<0.01$ and ${ }^{9} p<0.05$ as compared with EC single formula; ${ }^{\mathrm{h}} p<0.01$ as compared with $A R$ single formula.

Table 8. Femoral and Tibial AC with SM SOX9 mRNA Expressions in Sham-Operated or OA Rats

\begin{tabular}{|c|c|c|c|}
\hline \multirow[b]{2}{*}{ Groups } & \multicolumn{3}{|c|}{ SOX9 mRNA expressions } \\
\hline & Femoral AC & Tibial AC & SM \\
\hline \multicolumn{4}{|l|}{ Controls } \\
\hline Sham & $1.01 \pm 0.12$ & $1.01 \pm 0.17$ & $0.96 \pm 0.15$ \\
\hline OA & $0.28 \pm 0.07^{\mathrm{a}}$ & $0.26 \pm 0.07^{\mathrm{a}}$ & $0.19 \pm 0.09^{\mathrm{a}}$ \\
\hline Diclofenac & $0.57 \pm 0.13^{\mathrm{ab}}$ & $0.55 \pm 0.09^{\mathrm{ab}}$ & $0.45 \pm 0.11^{\mathrm{ab}}$ \\
\hline \multicolumn{4}{|l|}{ Single formula } \\
\hline PCP & $0.47 \pm 0.06^{\mathrm{ab}}$ & $0.46 \pm 0.08^{\mathrm{ab}}$ & $0.41 \pm 0.06^{\mathrm{ab}}$ \\
\hline $\mathrm{EC}$ & $0.43 \pm 0.08^{\mathrm{ab}}$ & $0.42 \pm 0.06^{\mathrm{ab}}$ & $0.39 \pm 0.08^{\mathrm{ab}}$ \\
\hline $\mathrm{AR}$ & $0.42 \pm 0.08^{\mathrm{ab}}$ & $0.42 \pm 0.08^{\mathrm{ab}}$ & $0.32 \pm 0.07^{\mathrm{ab}}$ \\
\hline \multicolumn{4}{|c|}{ Mixed formula - PCP and EC:AR } \\
\hline $1: 1$ & $0.59 \pm 0.07^{\text {abceg }}$ & $0.56 \pm 0.10^{\text {abdeg }}$ & $0.51 \pm 0.06^{\text {abdeg }}$ \\
\hline $1: 2$ & $0.56 \pm 0.05^{\text {abdeg }}$ & $0.55 \pm 0.07$ abeg & $0.50 \pm 0.07$ abdeg \\
\hline $1: 4$ & $0.56 \pm 0.09$ abdeg & $0.56 \pm 0.11$ abdeg & $0.48 \pm 0.07^{\mathrm{abfg}}$ \\
\hline $1: 6$ & $0.47 \pm 0.08^{\mathrm{ab}}$ & $0.48 \pm 0.13^{\mathrm{ab}}$ & $0.39 \pm 0.099^{\mathrm{ab}}$ \\
\hline $1: 8$ & $0.43 \pm 0.05^{\mathrm{ab}}$ & $0.42 \pm 0.10^{\mathrm{ab}}$ & $0.38 \pm 0.10^{\mathrm{ab}}$ \\
\hline $2: 1$ & $0.61 \pm 0.05^{\text {abceg }}$ & $0.61 \pm 0.11$ abceg & $0.56 \pm 0.09$ abceg \\
\hline $4: 1$ & $0.69 \pm 0.10^{\text {abceg }}$ & $0.68 \pm 0.10^{\text {abceg }}$ & $0.65 \pm 0.11$ abceg \\
\hline $6: 1$ & $0.48 \pm 0.09^{\mathrm{ab}}$ & $0.48 \pm 0.11^{\mathrm{ab}}$ & $0.35 \pm 0.10^{\mathrm{ab}}$ \\
\hline $8: 1$ & $0.46 \pm 0.10^{\mathrm{ab}}$ & $0.44 \pm 0.11^{\mathrm{ab}}$ & $0.35 \pm 0.09^{\mathrm{ab}}$ \\
\hline
\end{tabular}

Values are expressed mean $\pm \mathrm{SD}$ of 10 rats, Relative to control $/ \beta$-actin. $\mathrm{AR}=$ Aqueous extracts of Achyranthis Radix, $\mathrm{OA}=$ Osteoarthritis; $\mathrm{EC}=$ Aqueous extracts of Eucommiae Cortex, $\mathrm{PCP}=$ Pomegranate Concentration Powder; $\mathrm{AC}=$ Articular cartilage; $\mathrm{SM}$ $=$ Synovial membrane; SOX9 $=$ SRY (sex determining region Y)-box $9 .{ }^{a} p<0.01$ as compared with sham control; ${ }^{b} p<0.01$ as compared with OA control; ${ }^{c} p<0.01$ and ${ }^{d} p<0.05$ as compared with PCP single formula; ${ }^{\mathrm{e}} p<0.01$ and ${ }^{\dagger} p<0.05$ as compared with EC single formula; ${ }^{9} p<0.01$ as compared with AR single formula. 
(438) Journal of Korean Medicine 2017;38(4)

Table 9. Femoral and Tibial AC with SM Aggrecan mRNA Expressions in Sham-Operated or OA Rats

\begin{tabular}{|c|c|c|c|}
\hline \multirow[b]{2}{*}{ Groups } & \multicolumn{3}{|c|}{ Aggrecan mRNA expressions } \\
\hline & Femoral AC & Tibial AC & SM \\
\hline \multicolumn{4}{|l|}{ Controls } \\
\hline Sham & $1.01 \pm 0.13$ & $0.97 \pm 0.16$ & $0.98 \pm 0.11$ \\
\hline $\mathrm{OA}$ & $0.19 \pm 0.06^{\mathrm{a}}$ & $0.16 \pm 0.06^{\mathrm{a}}$ & $0.19 \pm 0.04^{\mathrm{a}}$ \\
\hline Diclofenac & $0.54 \pm 0.10^{\mathrm{ab}}$ & $0.43 \pm 0.11^{\mathrm{ab}}$ & $0.45 \pm 0.09^{a b}$ \\
\hline \multicolumn{4}{|l|}{ Single formula } \\
\hline PCP & $0.41 \pm 0.08$ ab & $0.32 \pm 0.06^{\mathrm{ab}}$ & $0.35 \pm 0.06^{\mathrm{ab}}$ \\
\hline $\mathrm{EC}$ & $0.32 \pm 0.07^{\mathrm{ab}}$ & $0.28 \pm 0.07^{\mathrm{ab}}$ & $0.32 \pm 0.08^{\mathrm{ab}}$ \\
\hline $\mathrm{AR}$ & $0.32 \pm 0.05^{\mathrm{ab}}$ & $0.26 \pm 0.09^{\mathrm{ab}}$ & $0.30 \pm 0.06^{\mathrm{ab}}$ \\
\hline \multicolumn{4}{|c|}{ Mixed formula - PCP and EC:AR } \\
\hline $1: 1$ & $0.51 \pm 0.06^{\text {abdeg }}$ & $0.43 \pm 0.96^{\text {abceg }}$ & $0.44 \pm 0.05$ abdeg \\
\hline $1: 2$ & $0.50 \pm 0.07^{\text {abdeg }}$ & $0.42 \pm 0.06^{\text {abceg }}$ & $0.42 \pm 0.06^{\text {abdeg }}$ \\
\hline $1: 4$ & $0.49 \pm 0.07^{\text {abdeg }}$ & $0.39 \pm 0.06^{\text {abdeg }}$ & $0.41 \pm 0.06^{\text {abfg }}$ \\
\hline $1: 6$ & $0.39 \pm 0.13^{\mathrm{ab}}$ & $0.32 \pm 0.08^{\mathrm{ab}}$ & $0.36 \pm 0.09$ ab \\
\hline $1: 8$ & $0.35 \pm 0.099^{a b}$ & $0.28 \pm 0.08^{a b}$ & $0.35 \pm 0.07^{\mathrm{ab}}$ \\
\hline $2: 1$ & $0.59 \pm 0.07^{\text {abceg }}$ & $0.47 \pm 0.07^{\text {abceg }}$ & $0.48 \pm 0.07^{\text {abceg }}$ \\
\hline $4: 1$ & $0.61 \pm 0.10^{\text {abceg }}$ & $0.52 \pm 0.09^{\text {abceg }}$ & $0.58 \pm 0.09$ abceg \\
\hline $6: 1$ & $0.37 \pm 0.11^{\mathrm{ab}}$ & $0.30 \pm 0.09^{\mathrm{ab}}$ & $0.35 \pm 0.08^{a b}$ \\
\hline $8: 1$ & $0.35 \pm 0.08^{a b}$ & $0.29 \pm 0.09^{\mathrm{ab}}$ & $0.32 \pm 0.11^{\mathrm{ab}}$ \\
\hline
\end{tabular}

Values are expressed mean $\pm S D$ of 10 rats, Relative to control $/ \beta$-actin. $A R=$ Aqueous extracts of Achyranthis Radix, $\mathrm{OA}=$ Osteoarthritis; $\mathrm{EC}=$ Aqueous extracts of Eucommiae Cortex, $\mathrm{PCP}=$ Pomegranate Concentration Powder; $\mathrm{AC}=$ Articular cartilage; $\mathrm{SM}$ $=$ Synovial membrane. ${ }^{a} p<0.01$ as compared with sham control; ${ }^{b} p<0.01$ as compared with OA control; ${ }^{c} p<0.01$ and ${ }^{d} p<0.05$ as compared with PCP single formula; ${ }^{\mathrm{e}} p<0.01$ and ${ }^{\dagger} p<0.05$ as compared with EC single formula; ${ }^{9} p<0.01$ as compared with AR single formula.

Table 10. Femoral and Tibial AC with SM BrdU-Immunoreactive Cell Numbers in Sham-Operated or OA Rats

\begin{tabular}{|c|c|c|c|c|}
\hline \multirow[b]{2}{*}{ Groups } & \multirow[t]{2}{*}{ Items } & \multicolumn{3}{|c|}{ BrdU-immunoreactive cell numbers } \\
\hline & & Femoral AC & Tibial AC & SM \\
\hline \multicolumn{5}{|l|}{ Controls } \\
\hline Sham & & $31.70 \pm 5.65$ & $25.90 \pm 4.53$ & $7.50 \pm 2.55$ \\
\hline OA & & $3.90 \pm 1.52^{\mathrm{a}}$ & $3.70 \pm 1.25^{\mathrm{a}}$ & $275.90 \pm 88.78^{\mathrm{a}}$ \\
\hline Diclofenac & & $4.20 \pm 1.62^{\mathrm{a}}$ & $3.90 \pm 0.99^{\mathrm{a}}$ & $50.00 \pm 14.79^{\mathrm{ac}}$ \\
\hline \multicolumn{5}{|c|}{ Single formula } \\
\hline PCP & & $15.90 \pm 3.38$ ac & $15.50 \pm 3.89^{\mathrm{ac}}$ & $107.60 \pm 21.75^{\mathrm{ac}}$ \\
\hline $\mathrm{EC}$ & & $11.20 \pm 1.81^{\text {ac }}$ & $11.00 \pm 2.83^{\mathrm{ac}}$ & $151.10 \pm 19.14^{\text {ac }}$ \\
\hline $\mathrm{AR}$ & & $10.30 \pm 2.54^{\mathrm{ac}}$ & $10.90 \pm 2.23{ }^{\mathrm{ac}}$ & $135.00 \pm 19.67^{\mathrm{ac}}$ \\
\hline \multicolumn{5}{|c|}{ Mixed formula - PCP and EC:AR } \\
\hline $1: 1$ & & $26.50 \pm 7.89^{\mathrm{cdfg}}$ & $27.40 \pm 4.79^{\mathrm{cdfg}}$ & $62.70 \pm 11.55^{\mathrm{acdfg}}$ \\
\hline $1: 2$ & & $22.50 \pm 2.88^{\text {acdfg }}$ & $20.50 \pm 2.27$ acdfg & $76.50 \pm 10.60^{\text {acdfg }}$ \\
\hline $1: 4$ & & $17.70 \pm 2.98^{\text {acfg }}$ & $17.10 \pm 2.60^{\mathrm{acfg}}$ & $78.20 \pm 14.88$ acdfg \\
\hline $1: 6$ & & $13.60 \pm 5.19$ ace & $12.80 \pm 3.08^{\mathrm{ac}}$ & $127.60 \pm 35.84^{\mathrm{ac}}$ \\
\hline $1: 8$ & & $13.40 \pm 5.40^{\text {ace }}$ & $12.40 \pm 4.35^{\mathrm{ac}}$ & $134.70 \pm 40.95^{\mathrm{ac}}$ \\
\hline $2: 1$ & & $38.80 \pm 6.71$ bdfg & $33.00 \pm 8.03$ bcdfg & $52.50 \pm 10.41$ acdfg \\
\hline $4: 1$ & & $48.70 \pm 6.65^{\text {acdfg }}$ & $39.00 \pm 6.55^{\text {acdfg }}$ & $44.50 \pm 10.54^{\text {acdfg }}$ \\
\hline $6: 1$ & & $13.60 \pm 4.27^{\mathrm{ac}}$ & $14.80 \pm 7.67^{\mathrm{ac}}$ & $119.50 \pm 77.76^{\mathrm{ac}}$ \\
\hline $8: 1$ & & $13.20 \pm 3.97^{\mathrm{ac}}$ & $12.30 \pm 6.53$ ace & $124.50 \pm 50.35^{\mathrm{ac}}$ \\
\hline
\end{tabular}

Values are expressed mean \pm SD of 10 rats, cells $/ \mathrm{mm}^{2}$. AR = Aqueous extracts of Achyranthis Radix, OA = Osteoarthritis; EC = Aqueous extracts of Eucommiae Cortex, $\mathrm{PCP}=$ Pomegranate Concentration Powder; $\mathrm{AC}=$ Articular cartilage; $\mathrm{SM}=\mathrm{Synovial}$ membrane; BrdU = 5-Bromo-2' -Deoxyuridine. ' $p<0.01$ and ${ }^{\circ} p<0.05$ as compared with sham control; ' $p<0.01$ as compared with $0 A$ control; ' $p<$ 0.01 and ${ }^{\mathrm{e}} p<0.05$ as compared with PCP single formula; ${ }^{\dagger} p<0.01$ as compared with EC single formula; ${ }^{g} p<0.01$ as compared with AR single formula. 


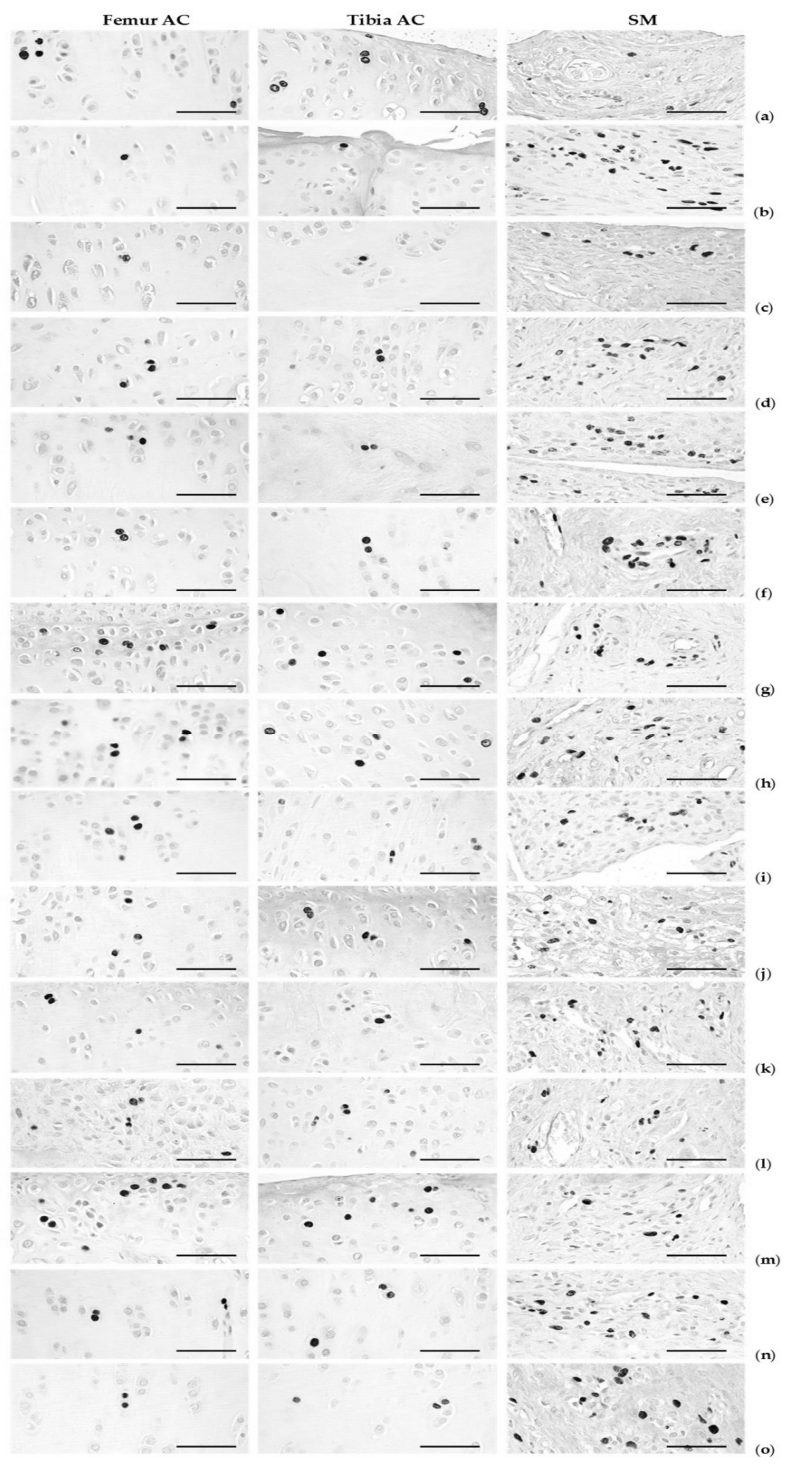

Fig. 4. Representative immunohistochemistrical images of the BrdU-immunoreactive cells on the femur and tibia AC with SM, taken from sham-operated or OA Rats. (a) Sham vehicle control (Sham-operated and distilled water orally administered rats); (b) OA control (OA-surgery and distilled water orally administered rats); (c) Diclofenac (OA-surgery and diclofenac sodium $2 \mathrm{mg} / \mathrm{kg}$ subcutaneously treated rats); (d) PCP (OA-surgery and PCP single formula $200 \mathrm{mg} / \mathrm{kg}$ orally administered rats); (e) EC (OA-surgery and EC single formula $200 \mathrm{mg} / \mathrm{kg}$ orally administered rats); (f) AR (OA-surgery and AR single formula $200 \mathrm{mg} / \mathrm{kg}$ orally administered rats); (g) PCP $100 \mathrm{mg}$ with EC:AR 1:1 (50:50 mg:mg) mixed formula administered OA rats; (h) PCP $100 \mathrm{mg}$ with EC:AR 1:2 (33:67 mg:mg) mixed formula administered OA rats; (i) PCP 100 mg with EC:AR 1:4 (20:80 mg:mg) mixed formula administered OA rats; (j) PCP 100 mg with EC:AR 1:6 (14:86 mg:mg) mixed formula administered OA rats; (k) PCP 100 mg with EC:AR 1:8 (11:89 mg:mg) mixed formula administered OA rats; (I) PCP $100 \mathrm{mg}$ with EC:AR 2:1 (67:33 mg:mg) mixed formula administered OA rats; (m) PCP 100 mg with EC:AR 4:1 (80:20 mg:mg) mixed formula administered OA rats; (n) PCP $100 \mathrm{mg}$ with EC:AR 6:1 (86:14 mg:mg) mixed formula administered OA rats; (o) PCP $100 \mathrm{mg}$ with EC:AR 8:1 (89:11 mg:mg) mixed formula administered OA rats. $\mathrm{AR}=$ Aqueous extracts of Achyranthis Radix, OA = Osteoarthritis; EC $=$ Aqueous extracts of Eucommiae Cortex, PCP = Pomegranate Concentration Powder; BrdU = 5-Bromo-2'-Deoxyuridine; $\mathrm{ABC}=$ Avidin-biotin complex. All ABC immunostain. Scale bars $=120 \mu \mathrm{m}$. 
(440) Journal of Korean Medicine 2017;38(4)

Table 11. Femoral AC Mankin Scores in Sham-Operated or OA Rats

\begin{tabular}{|c|c|c|c|c|c|}
\hline \multirow[b]{2}{*}{ Groups } & \multicolumn{5}{|c|}{ Mankin scores } \\
\hline & Surface & Hypocellularity & Clone & Stain intensity & Total* \\
\hline \multicolumn{6}{|l|}{ Controls } \\
\hline Sham & $0.80 \pm 0.63$ & $0.30 \pm 0.48$ & $0.20 \pm 0.42$ & $0.40 \pm 0.52$ & $1.70 \pm 1.25$ \\
\hline OA & $2.60 \pm 0.52^{\mathrm{a}}$ & $2.60 \pm 0.52^{\mathrm{a}}$ & $2.60 \pm 0.52^{\mathrm{a}}$ & $2.30 \pm 0.67^{\mathrm{a}}$ & $10.10 \pm 0.99^{\mathrm{a}}$ \\
\hline Diclofenac & $1.40 \pm 0.70 \mathrm{bc}$ & $1.30 \pm 0.48^{\text {ac }}$ & $0.90 \pm 0.57 \mathrm{bc}$ & $1.30 \pm 0.48^{\mathrm{ac}}$ & $4.90 \pm 1.20^{\mathrm{ac}}$ \\
\hline \multicolumn{6}{|l|}{ Single formula } \\
\hline PCP & $2.30 \pm 0.48^{\mathrm{a}}$ & $1.60 \pm 0.52 \mathrm{ac}$ & $1.80 \pm 0.63{ }^{\mathrm{ac}}$ & $1.80 \pm 0.42$ ac & $7.50 \pm 0.97$ ac \\
\hline $\mathrm{EC}$ & $2.20 \pm 0.63$ & $2.00 \pm 0.67^{\mathrm{ad}}$ & $1.90 \pm 0.57 \mathrm{ad}$ & $2.00 \pm 0.67^{\mathrm{a}}$ & $8.10 \pm 1.60^{\mathrm{ac}}$ \\
\hline $\mathrm{AR}$ & $2.40 \pm 0.52^{\mathrm{a}}$ & $1.90 \pm 0.74$ ac & $2.10 \pm 0.57^{\mathrm{a}}$ & $2.10 \pm 0.57^{\mathrm{a}}$ & $8.50 \pm 0.71$ ac \\
\hline \multicolumn{6}{|c|}{ Mixed formula - PCP and EC:AR } \\
\hline $1: 1$ & $1.50 \pm 0.53$ bcehi & $1.80 \pm 0.63^{\mathrm{ac}}$ & $1.10 \pm 0.57$ acfgi & $1.20 \pm 0.42$ acfgi & $5.60 \pm 0.84$ acegi \\
\hline $1: 2$ & $1.80 \pm 0.63$ acj & $1.10 \pm 0.57 \mathrm{acgi}$ & $1.40 \pm 0.84$ acj & $1.40 \pm 0.52$ achj & $5.70 \pm 1.16^{\text {acegi }}$ \\
\hline $1: 4$ & $1.50 \pm 0.71$ bcehi & $1.50 \pm 0.53^{\mathrm{ac}}$ & $1.30 \pm 0.48$ & $1.50 \pm 0.53$ acj & $5.80 \pm 1.23$ \\
\hline $1: 6$ & $2.30 \pm 0.48^{\mathrm{a}}$ & $1.90 \pm 0.57^{\mathrm{ac}}$ & $1.90 \pm 0.74^{\mathrm{ad}}$ & $1.80 \pm 0.79^{\mathrm{a}}$ & $7.90 \pm 0.88^{\mathrm{ac}}$ \\
\hline $1: 8$ & $2.30 \pm 0.67^{\mathrm{a}}$ & $1.90 \pm 0.57^{\mathrm{ac}}$ & $2.00 \pm 0.67^{\mathrm{ad}}$ & $1.90 \pm 0.57^{\mathrm{a}}$ & $8.10 \pm 1.79^{\mathrm{ac}}$ \\
\hline $2: 1$ & $1.50 \pm 0.53$ bcehi & $1.30 \pm 0.48{ }^{\mathrm{acgj}}$ & $1.50 \pm 0.53$ & $1.10 \pm 0.57^{\text {bcfgi }}$ & $5.40 \pm 1.26$ \\
\hline $4: 1$ & $1.60 \pm 0.52$ acfhi & $1.30 \pm 0.67^{\mathrm{acgj}}$ & $1.10 \pm 0.57$ acfgi & $1.10 \pm 0.57^{\text {bcfgi }}$ & $5.10 \pm 1.20$ \\
\hline $6: 1$ & $2.00 \pm 0.67^{\mathrm{ad}}$ & $1.80 \pm 0.63^{\mathrm{ac}}$ & $1.90 \pm 0.57^{\mathrm{ad}}$ & $1.70 \pm 0.82^{\mathrm{ad}}$ & $7.40 \pm 1.78^{\mathrm{ac}}$ \\
\hline $8: 1$ & $2.10 \pm 0.74^{\mathrm{a}}$ & $1.60 \pm 0.70^{\mathrm{ac}}$ & $1.80 \pm 0.63{ }^{\mathrm{ac}}$ & $2.00 \pm 0.82^{\mathrm{a}}$ & $7.50 \pm 1.72^{\mathrm{ac}}$ \\
\hline
\end{tabular}

Values are expressed mean $\pm \mathrm{SD}$ of 10 rats, score $\left({ }^{*}\right.$ Max of totalized scores $\left.=12\right)$. AR $=$ Aqueous extracts of Achyranthis Radix, $\mathrm{OA}$ $=$ Osteoarthritis; $\mathrm{EC}=$ Aqueous extracts of Eucommiae Cortex, $\mathrm{PCP}=$ Pomegranate Concentration Powder; $\mathrm{AC}=$ Articular cartilage; SM $=$ Synovial membrane ${ }^{a} p<0.01$ and ${ }^{b} p<0.05$ as compared with sham control; ${ }^{c} p<0.01$ and ${ }^{d} p<0.05$ as compared with $0 A$ control; ${ }^{\mathrm{e}} p<0.01$ and ${ }^{\dagger} p<0.05$ as compared with PCP single formula; ${ }^{g} p<0.01$ and ${ }^{h} p<0.05$ as compared with EC single formula; ${ }^{i} p<0.01$ and ${ }^{\mathrm{j}} p<0.05$ as compared with AR single formula.

Table 12. Tibial AC Mankin Scores in Sham-Operated or OA Rats

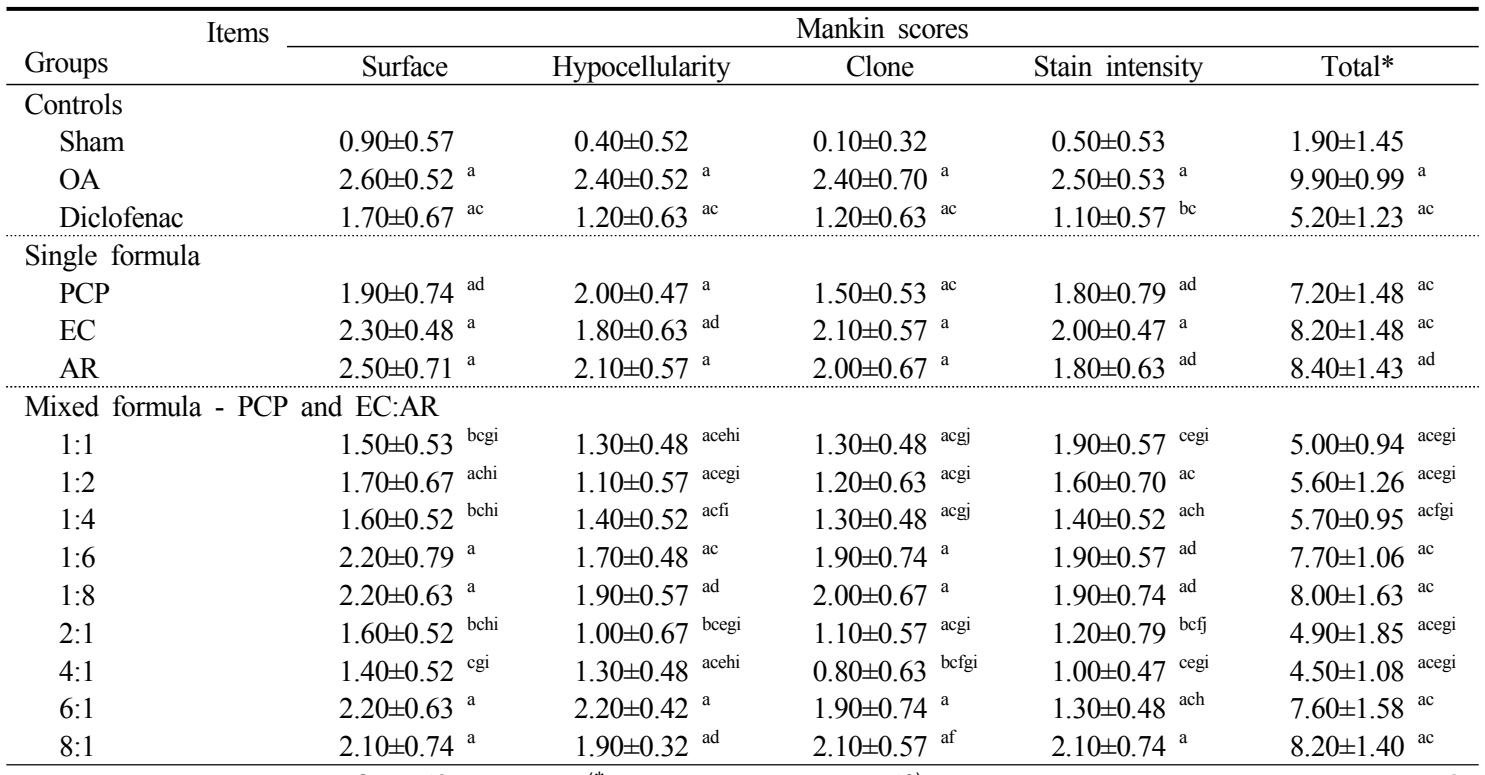

Values are expressed mean \pm SD of 10 rats, score ( ${ }^{*}$ Max of totalized scores $\left.=12\right)$. AR = Aqueous extracts of Achyranthis Radix, OA $=$ Osteoarthritis; $E C=$ Aqueous extracts of Eucommiae Cortex, $\mathrm{PCP}=$ Pomegranate Concentration Powder; $\mathrm{AC}=$ Articular cartilage; $\mathrm{SM}$ $=$ Synovial membrane. ${ }^{a} p<0.01$ and ${ }^{b} p<0.05$ as compared with sham control; ${ }^{c} p<0.01$ and ${ }^{d} p<0.05$ as compared with $0 A$ control; ${ }^{\mathrm{e}} p<0.01$ and ${ }^{\dagger} p<0.05$ as compared with PCP single formula; ${ }^{g} p<0.01$ and ${ }^{h} p<0.05$ as compared with EC single formula; ${ }^{i} p<0.01$ and ${ }^{\mathrm{j}} p<0.05$ as compared with AR single formula. 
chondrocytes and clones, and decreased Safranin-O stain intensity on femoral and tibial AC. Consequently, significant increases $(p<0.01)$ in femoral and tibial $\mathrm{AC}$ Mankin scores were observed in OA control rats compared with scores in sham control rats. However, femoral and tibial AC Mankin scores decreased significantly $(p<0.01$ or $p<0.05)$ in all test-substance -treated rats compared with values in OA control rats. In particular, PCP and the EC:AR 4:1, 2:1, 1:1, $1: 2$, and 1:4 mixed formulas caused significant decreases $(p<0.01$ or $p<0.05)$ in femoral and tibial AC Mankin scores compared with each single formula (in that order) (Figure 5, Table 11 and 12).

\section{Changes in the general histopathology of femoral and tibial AC with SM tissue}

Femoral and tibial AC thicknesses decreased significantly $(p<0.01)$ in $\mathrm{OA}$ control rats compared with thicknesses in sham control rats; however, significant increases in femoral $(p<0.01$ or $p<0.05)$ and tibial $(p<0.01) \mathrm{AC}$ thicknesses were observed in all test-substance-treated rats compared with values in OA control rats. In particular, the PCP and EC:AR 4:1, 2:1, 1:1, 1:2, and 1:4 mixed formulas induced significant increases in femoral $(p<0.01)$ and tibial $(p<0.01$ or $p<0.05)$ AC thicknesses compared with each single formula (in that order) (Figure 5, Table 13).

The SM lining epithelium thickness increased significantly $(p<0.01)$ in $\mathrm{OA}$ control rats compared with values in sham control rats, whereas the SM lining epithelium thickness decreased significantly $(p<0.01)$ in all test substance-treated rats, including the PCP and EC:AR 8:1 mixed-formula-treated OA rats, compared with values in OA control rats. In particular, the PCP and EC:AR 4:1, 2:1, 1:1, 1:2, and 1:4 mixed formulas caused significant decreases $(p<0.01)$ in SM tissue lining epithelium thickness compared with each single formula (in that order) (Figure 5, Table 13).
The number of inflammatory cells infiltrating the SM tissue increased significantly $(p<0.01)$ in $\mathrm{OA}$ control rats compared with numbers in sham control rats, whereas the number of inflammatory cells infiltrating the SM tissue decreased significantly $(p<0.01)$ in all test-substance-treated rats, including the diclofenac-treated OA rats, compared with numbers in OA control rats. In particular, the PCP and EC:AR 4:1, 2:1, 1:1, 1:2, and 1:4 mixed formulas caused significant decreases $(p<0.01$ or $p<0.05$ ) in the numbers of inflammatory cells infiltrating the SM tissue compared with each single formula (in that order) (Figure 5, Table 13).

\section{Effects on inhibiting inflammation and apoptosis in femoral and tibial AC with SM tissue}

The numbers of PARP, COX-2, and TNF- $a$ -immunopositive cells in femoral and tibial $\mathrm{AC}$ with SM tissue increased significantly $(p<0.01)$ in $\mathrm{OA}$ control rats, whereas the numbers of these cells decreased significantly $(p<0.01$ or $p<0.05)$ in all test-substance-treated rats compared with numbers in OA control rats. In particular, the PCP and EC:AR $4: 1, \quad 2: 1, \quad 1: 1$, and 1:2 mixed formulas caused significant decreases $(p<0.01)$ in the numbers of PARP-immunolabeled cells (Figure 6, Table 14), and the PCP and EC:AR 4:1, 2:1, 1:1, 1:2, and 1:4 mixed formulas induced significant decreases $(p<0.01$ or $p<0.05)$ in the numbers of COX2 and TNF-a -immunolabeled cells in the femoral and tibial AC (Figure 7 and 8, Table 15 and 16), as well as in the SM tissue, compared with each single formula (in that order).

\section{Discussion}

OA also known as degenerative joint diseases, and is one of chronic inflammatory diseases. The cartilage damages in $\mathrm{OA}$ lead to production of $\mathrm{PGE}_{2}$ 
(442) Journal of Korean Medicine 2017;38(4)

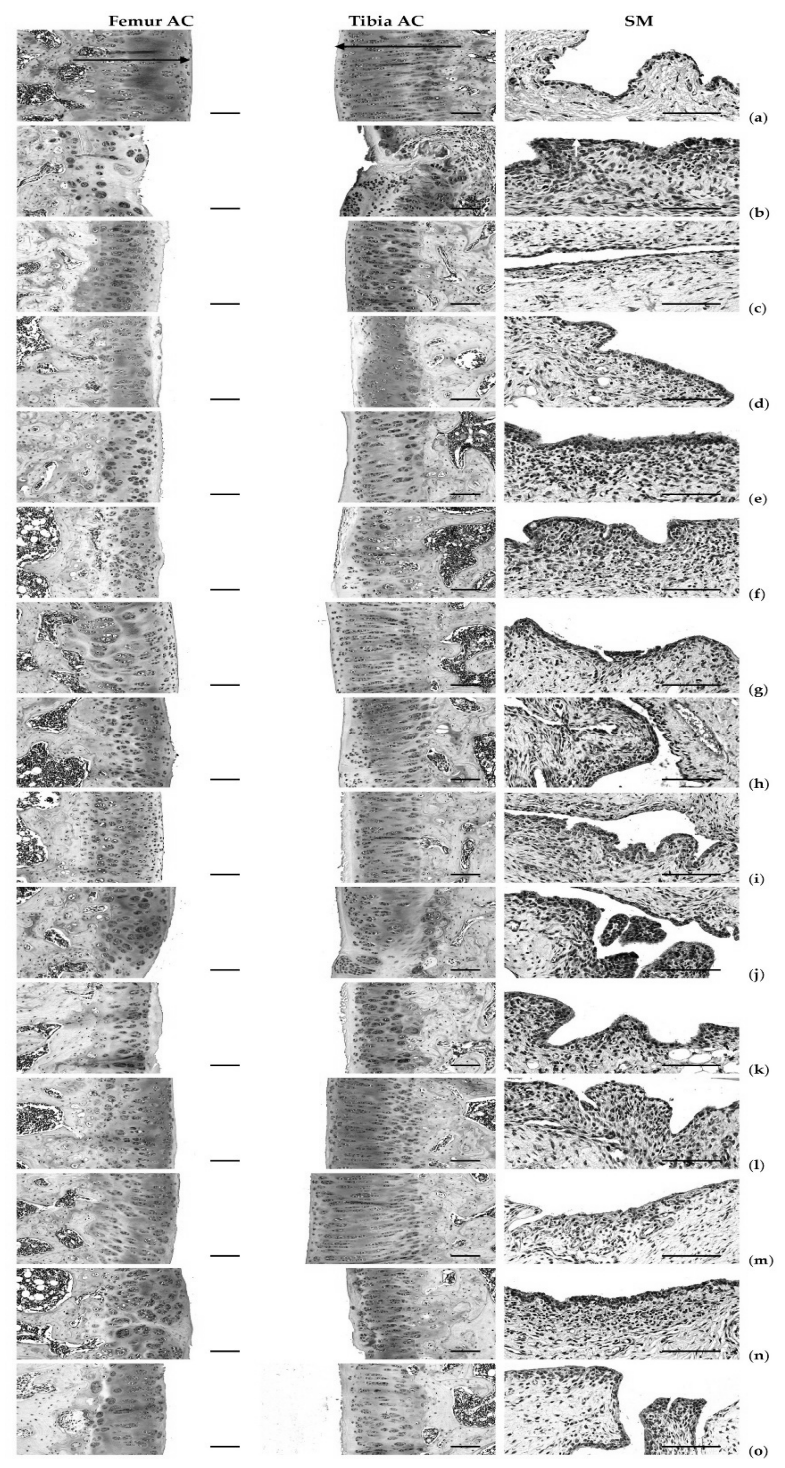

Fig. 5. Representative general histological images of the femur and tibia AC with SM, taken from sham-operated or OA Rats. (a) Sham vehicle control (Sham-operated and distilled water orally administered rats); (b) OA control (OA-surgery and distilled water orally administered rats); (c) Diclofenac (OA-surgery and diclofenac sodium $2 \mathrm{mg} / \mathrm{kg}$ subcutaneously treated rats); (d) PCP (OA-surgery and PCP single formula $200 \mathrm{mg} / \mathrm{kg}$ orally administered rats); (e) EC (OA-surgery and EC single formula $200 \mathrm{mg} / \mathrm{kg}$ orally administered rats); (f) AR (OA-surgery and AR single formula $200 \mathrm{mg} / \mathrm{kg}$ orally administered rats); (g) PCP $100 \mathrm{mg}$ with EC:AR 1:1 (50:50 mg:mg) mixed formula administered OA rats; (h) PCP $100 \mathrm{mg}$ with EC:AR 1:2 (33:67 mg:mg) mixed formula administered OA rats; (i) PCP $100 \mathrm{mg}$ with EC:AR 1:4 (20:80 mg:mg) mixed formula administered OA rats; (j) PCP $100 \mathrm{mg}$ with EC:AR 1:6 (14:86 mg:mg) mixed formula administered OA rats; (k) PCP 100 mg with EC:AR 1:8 (11:89 mg:mg) mixed formula administered OA rats; (I) PCP 100 mg with EC:AR 2:1 (67:33 mg:mg) mixed formula administered OA rats; (m) PCP 100 mg with EC:AR 4:1 (80:20 mg:mg) mixed formula administered OA rats; (n) PCP 100 mg with EC:AR 6:1 (86:14 mg:mg) mixed formula administered OA rats; (o) PCP $100 \mathrm{mg}$ with EC:AR 8:1 (89:11 mg:mg) mixed formula administered OA rats. AR = Aqueous extracts of Achyranthis Radix, OA = Osteoarthritis; EC = Aqueous extracts of Eucommiae Cortex, PCP $=$ Pomegranate Concentration Powder; BrdU = 5-Bromo-2'-Deoxyuridine. Arrows indicated the thicknesses of tibia or femur AC or of SM lining epithelium. All Safranin O stain. Scale bars $=120 \mu \mathrm{m}$. 


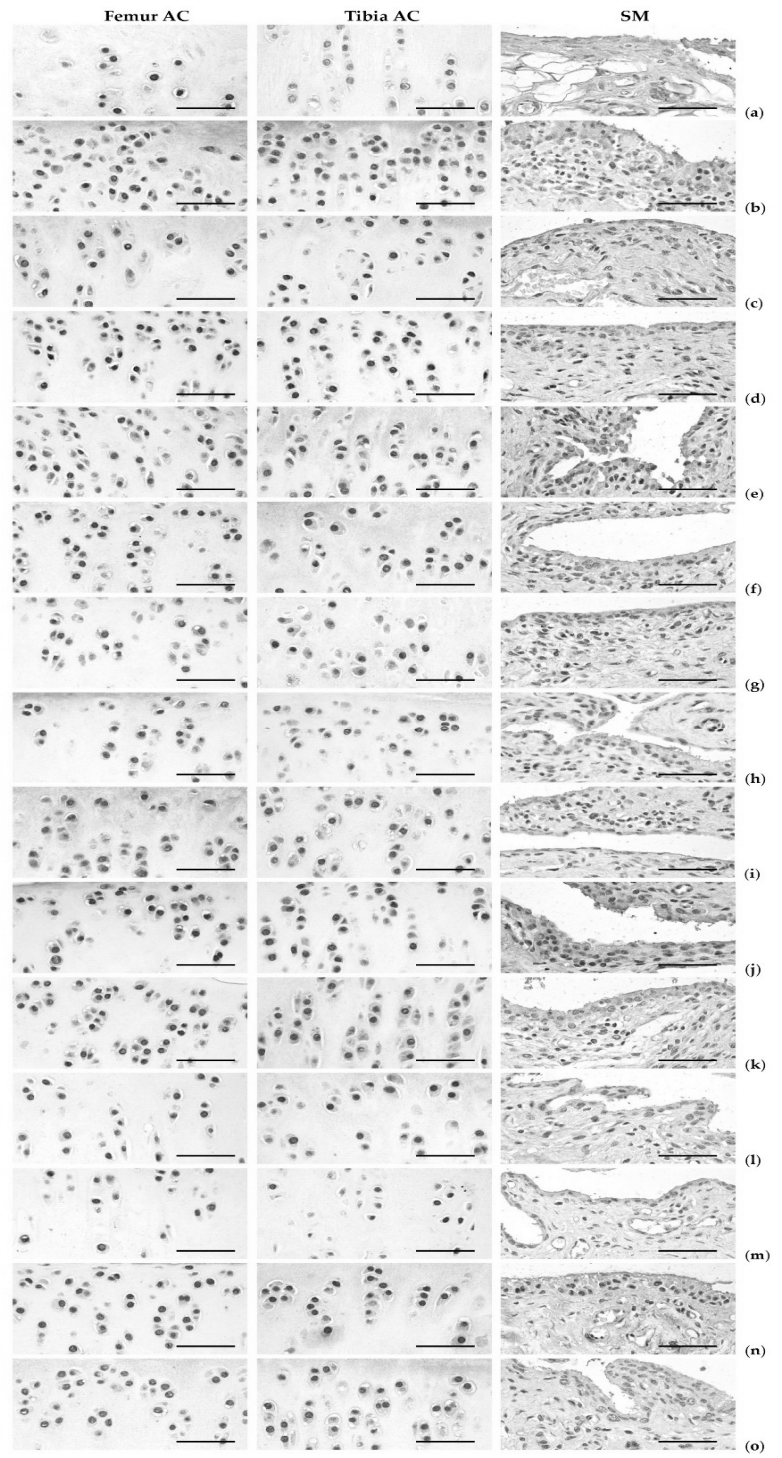

Fig. 6. Representative immunohistochemistrical images of the PARP-immunoreactive cells on the femur and tibia AC with SM, taken from sham-operated or OA Rats. (a) Sham vehicle control (Sham-operated and distilled water orally administered rats); (b) OA control (OA-surgery and distilled water orally administered rats); (c) Diclofenac (OA-surgery and diclofenac sodium $2 \mathrm{mg} / \mathrm{kg}$ subcutaneously treated rats); (d) PCP (OA-surgery and PCP single formula $200 \mathrm{mg} / \mathrm{kg}$ orally administered rats); (e) EC (OA-surgery and EC single formula $200 \mathrm{mg} / \mathrm{kg}$ orally administered rats); (f) AR (OA-surgery and AR single formula $200 \mathrm{mg} / \mathrm{kg}$ orally administered rats); (g) PCP $100 \mathrm{mg}$ with EC:AR 1:1 (50:50 mg:mg) mixed formula administered OA rats; (h) PCP $100 \mathrm{mg}$ with EC:AR 1:2 (33:67 mg:mg) mixed formula administered OA rats; (i) PCP $100 \mathrm{mg}$ with EC:AR 1:4 (20:80 mg:mg) mixed formula administered OA rats; (j) PCP 100 mg with EC:AR 1:6 (14:86 mg:mg) mixed formula administered OA rats; (k) PCP 100 mg with EC:AR 1:8 (11:89 mg:mg) mixed formula administered OA rats; (I) PCP $100 \mathrm{mg}$ with EC:AR 2:1 (67:33 mg:mg) mixed formula administered OA rats; (m) PCP $100 \mathrm{mg}$ with EC:AR 4:1 (80:20 mg:mg) mixed formula administered OA rats; (n) PCP $100 \mathrm{mg}$ with EC:AR 6:1 (86:14 mg:mg) mixed formula administered OA rats; (o) PCP $100 \mathrm{mg}$ with EC:AR 8:1 (89:11 mg:mg) mixed formula administered OA rats. AR = Aqueous extracts of Achyranthis Radix, OA = Osteoarthritis; EC $=$ Aqueous extracts of Eucommiae Cortex, $\mathrm{PCP}=$ Pomegranate Concentration Powder; $\mathrm{PARP}=$ Cleaved poly(ADP-ribose) polymerase; $A B C=$ Avidin-biotin complex. All ABC immunostain. Scale bars $=120 \mu \mathrm{m}$. 
(444) Journal of Korean Medicine 2017;38(4)

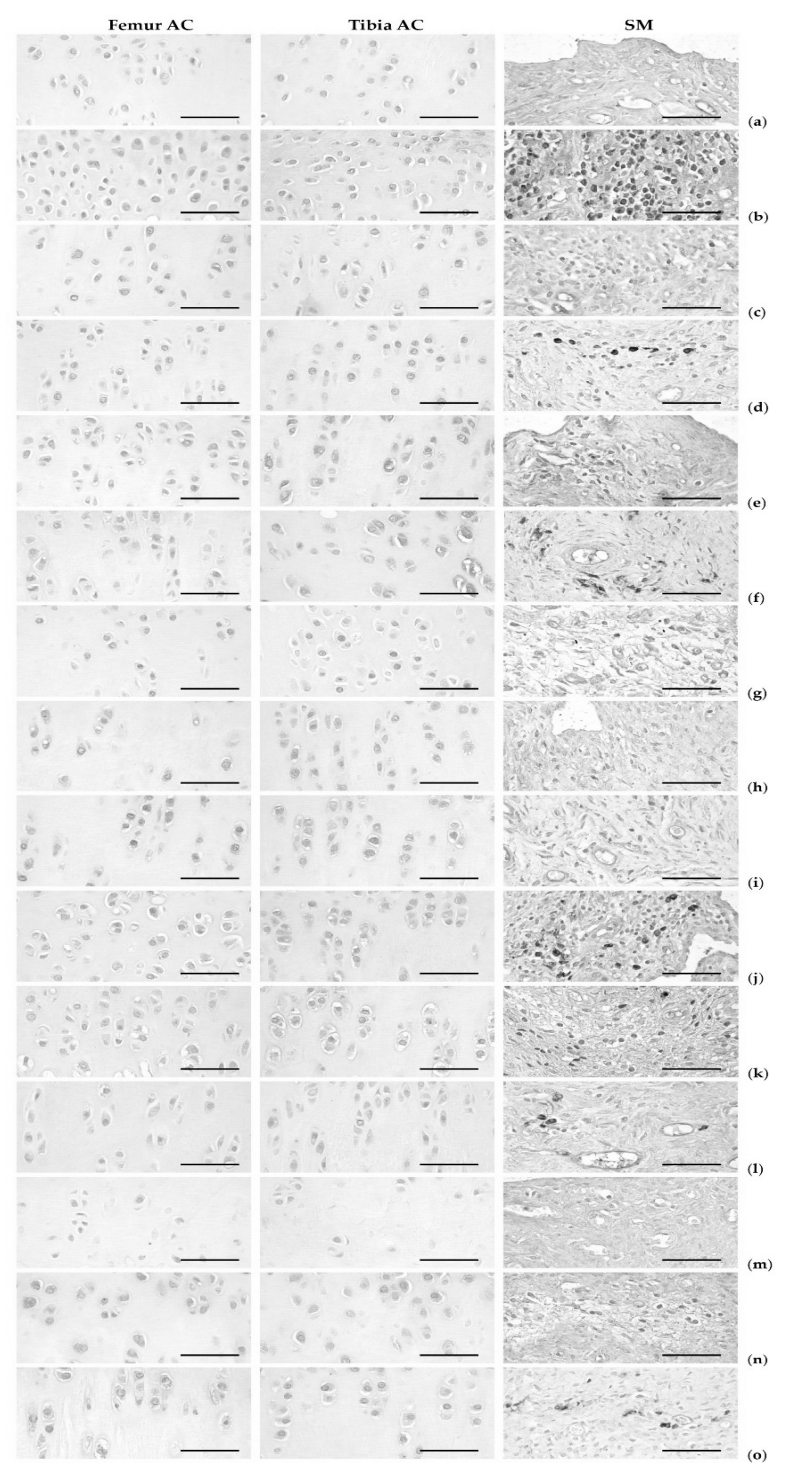

Fig. 7. Representative immunohistochemistrical images of the COX-2-immunoreactive cells on the femur and tibia AC with SM, taken from sham-operated or OA Rats. (a) Sham vehicle control (Sham-operated and distilled water orally administered rats); (b) OA control (OA-surgery and distilled water orally administered rats); (c) Diclofenac (OA-surgery and diclofenac sodium $2 \mathrm{mg} / \mathrm{kg}$ subcutaneously treated rats); (d) PCP (OA-surgery and PCP single formula $200 \mathrm{mg} / \mathrm{kg}$ orally administered rats); (e) EC (OA-surgery and EC single formula $200 \mathrm{mg} / \mathrm{kg}$ orally administered rats); (f) AR (OA-surgery and AR single formula $200 \mathrm{mg} / \mathrm{kg}$ orally administered rats); (g) PCP $100 \mathrm{mg}$ with EC:AR 1:1 (50:50 mg:mg) mixed formula administered OA rats; (h) PCP $100 \mathrm{mg}$ with EC:AR 1:2 (33:67 mg:mg) mixed formula administered OA rats; (i) PCP 100 mg with EC:AR 1:4 (20:80 mg:mg) mixed formula administered OA rats; (j) PCP 100 mg with EC:AR 1:6 (14:86 mg:mg) mixed formula administered OA rats; (k) PCP 100 mg with EC:AR 1:8 (11:89 mg:mg) mixed formula administered OA rats; (I) PCP $100 \mathrm{mg}$ with EC:AR 2:1 (67:33 mg:mg) mixed formula administered OA rats; (m) PCP 100 mg with EC:AR 4:1 (80:20 mg:mg) mixed formula administered OA rats; (n) PCP $100 \mathrm{mg}$ with EC:AR 6:1 (86:14 mg:mg) mixed formula administered OA rats; (o) PCP $100 \mathrm{mg}$ with EC:AR 8:1 (89:11 mg:mg) mixed formula administered OA rats. AR = Aqueous extracts of Achyranthis Radix, OA = Osteoarthritis; EC $=$ Aqueous extracts of Eucommiae Cortex, PCP = Pomegranate Concentration Powder; COX = Cyclooxygenase; $\mathrm{ABC}$ $=$ Avidin-biotin complex. All ABC immunostain. Scale bars $=120 \mu \mathrm{m}$. 


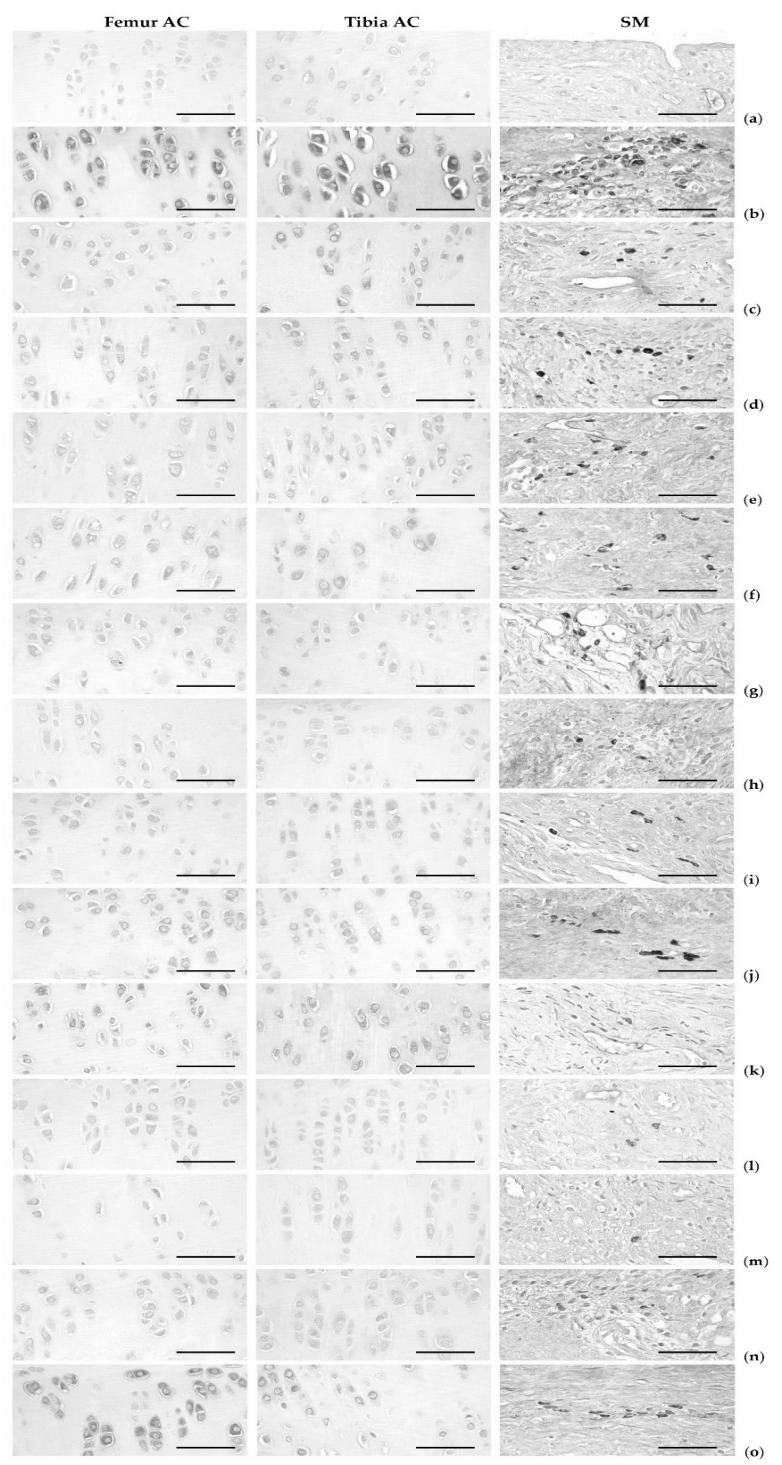

Fig. 8. Representative immunohistochemistrical images of the TNF- $\alpha$-immunoreactive cells on the femur and tibia AC with SM, taken from sham-operated or OA Rats. (a) Sham vehicle control (Sham-operated and distilled water orally administered rats); (b) OA control (OA-surgery and distilled water orally administered rats); (c) Diclofenac (OA-surgery and diclofenac sodium $2 \mathrm{mg} / \mathrm{kg}$ subcutaneously treated rats); (d) PCP (OA-surgery and PCP single formula $200 \mathrm{mg} / \mathrm{kg}$ orally administered rats); (e) EC (OA-surgery and EC single formula $200 \mathrm{mg} / \mathrm{kg}$ orally administered rats); (f) AR (OA-surgery and AR single formula $200 \mathrm{mg} / \mathrm{kg}$ orally administered rats); (g) PCP $100 \mathrm{mg}$ with EC:AR 1:1 (50:50 mg:mg) mixed formula administered OA rats; (h) PCP 100 mg with EC:AR 1:2 (33:67 mg:mg) mixed formula administered OA rats; (i) PCP $100 \mathrm{mg}$ with EC:AR 1:4 (20:80 mg:mg) mixed formula administered OA rats; (j) PCP 100 mg with EC:AR 1:6 (14:86 mg:mg) mixed formula administered OA rats; (k) PCP 100 mg with EC:AR 1:8 (11:89 mg:mg) mixed formula administered OA rats; (I) PCP $100 \mathrm{mg}$ with EC:AR 2:1 (67:33 mg:mg) mixed formula administered OA rats; (m) PCP 100 mg with EC:AR 4:1 (80:20 mg:mg) mixed formula administered OA rats; (n) PCP $100 \mathrm{mg}$ with EC:AR 6:1 (86:14 mg:mg) mixed formula administered OA rats; (o) PCP 100 mg with EC:AR 8:1 (89:11 mg:mg) mixed formula administered OA rats. $\mathrm{AR}=$ Aqueous extracts of Achyranthis Radix, OA = Osteoarthritis; EC $=$ Aqueous extracts of Eucommiae Cortex, PCP = Pomegranate Concentration Powder; TNF = Tumor necrosis factor; $\mathrm{ABC}=$ Avidin-biotin complex. All $\mathrm{ABC}$ immunostain. Scale bars $=120 \mu \mathrm{m}$. 
(446) Journal of Korean Medicine 2017;38(4)

Table 13. Femoral and Tibial AC with SM General Histomorphometrical Analysis in Sham-Operated or OA Rats

\begin{tabular}{|c|c|c|c|c|}
\hline \multirow[b]{2}{*}{ Groups } & \multicolumn{4}{|c|}{ General histomorphometry } \\
\hline & $\begin{array}{c}\text { Femoral } \mathrm{AC} \\
\text { thickness }(\mu \mathrm{m})\end{array}$ & $\begin{array}{c}\text { Tibial AC } \\
\text { thickness }(\mu \mathrm{m})\end{array}$ & $\begin{array}{l}\text { SM epithelial } \\
\text { thickness }(\mu \mathrm{m})\end{array}$ & $\begin{array}{l}\text { SM IF cell numbers } \\
\left(\times 10 \text { cells } / \mathrm{mm}^{2}\right)\end{array}$ \\
\hline \multicolumn{5}{|l|}{ Controls } \\
\hline Sham & $395.97 \pm 46.13$ & $413.22 \pm 58.94$ & $5.98 \pm 2.28$ & $2.06 \pm 1.00$ \\
\hline OA & $184.49 \pm 21.39^{\mathrm{a}}$ & $142.57 \pm 16.15^{\mathrm{a}}$ & $36.63 \pm 11.55^{\mathrm{a}}$ & $166.17 \pm 30.00^{\mathrm{a}}$ \\
\hline Diclofenac & $285.01 \pm 21.81^{\mathrm{ac}}$ & $285.71 \pm 32.62^{\mathrm{ac}}$ & $14.14 \pm 4.23{ }^{\text {ac }}$ & $27.86 \pm 16.41^{\mathrm{ac}}$ \\
\hline \multicolumn{5}{|l|}{ Single formula } \\
\hline PCP & $226.70 \pm 16.17$ ac & $247.68 \pm 17.97$ ac & $20.45 \pm 1.66^{\mathrm{ac}}$ & $79.12 \pm 14.88^{\text {ac }}$ \\
\hline $\mathrm{EC}$ & $219.89 \pm 16.70^{\mathrm{ac}}$ & $227.80 \pm 35.55^{\mathrm{ac}}$ & $24.43 \pm 5.03$ ac & $116.93 \pm 21.48^{\mathrm{ac}}$ \\
\hline $\mathrm{AR}$ & $209.23 \pm 15.92^{\text {ad }}$ & $200.36 \pm 37.20^{\mathrm{ac}}$ & $25.73 \pm 2.82^{\text {ac }}$ & $123.58 \pm 23.93{ }^{\mathrm{ac}}$ \\
\hline \multicolumn{5}{|c|}{ Mixed formula - PCP and EC:AR } \\
\hline $1: 1$ & $321.11 \pm 27.44^{\text {acegi }}$ & $319.45 \pm 28.82^{\text {acegi }}$ & $16.28 \pm 2.56^{\text {acegi }}$ & $48.91 \pm 10.60$ acegi \\
\hline $1: 2$ & $276.98 \pm 18.72$ & $295.33 \pm 34.93$ acegi & $17.21 \pm 2.08$ acegi & $60.05 \pm 13.76^{\text {acegi }}$ \\
\hline $1: 4$ & $274.97 \pm 21.51$ acegi & $274.05 \pm 29.68^{\text {acfgi }}$ & $17.65 \pm 1.64$ acegi & $62.32 \pm 11.74^{\text {acfgi }}$ \\
\hline $1: 6$ & $223.33 \pm 31.71$ ac & $227.24 \pm 46.60^{\mathrm{ac}}$ & $22.65 \pm 3.89^{\mathrm{ac}}$ & $81.52 \pm 21.88^{\text {acgi }}$ \\
\hline $1: 8$ & $218.38 \pm 29.26^{\mathrm{ac}}$ & $237.05 \pm 58.83^{\mathrm{ac}}$ & $24.46 \pm 4.74$ acf & $105.97 \pm 29.99^{\text {acf }}$ \\
\hline $2: 1$ & $324.14 \pm 30.98$ & $350.22 \pm 48.95$ bcegi & $13.03 \pm 2.18$ acegi & $39.26 \pm 9.30^{\text {acegi }}$ \\
\hline $4: 1$ & $333.88 \pm 25.31$ acegi & $373.79 \pm 31.66^{\mathrm{cegi}}$ & $11.98 \pm 2.84$ acegi & $31.51 \pm 8.16^{\text {acegi }}$ \\
\hline $6: 1$ & $229.59 \pm 38.57^{\mathrm{ac}}$ & $235.80 \pm 50.47^{\mathrm{ac}}$ & $22.61 \pm 6.32 \mathrm{ac}$ & $86.35 \pm 19.21$ \\
\hline $8: 1$ & $218.45 \pm 25.97^{\mathrm{ac}}$ & $223.00 \pm 50.33^{\mathrm{ac}}$ & $23.42 \pm 5.09{ }^{\mathrm{ac}}$ & $88.63 \pm 26.11$ achj \\
\hline
\end{tabular}

Values are expressed mean \pm SD of 10 rats. AR = Aqueous extracts of Achyranthis Radix, OA = Osteoarthritis; EC = Aqueous extracts of Eucommiae Cortex, PCP = Pomegranate Concentration Powder; $\mathrm{AC}=$ Articular cartilage; SM = Synovial membrane; IF = Inflammatory. ${ }^{a} p<0.01$ and ${ }^{b} p<0.05$ as compared with sham control; ${ }^{c} p<0.01$ and ${ }^{d} p<0.05$ as compared with $0 A$ control; ${ }^{e} p<0.01$ and ${ }^{\dagger} p<$ 0.05 as compared with PCP single formula; ${ }^{g} p<0.01$ and ${ }^{\mathrm{h}} p<0.05$ as compared with $\mathrm{EC}$ single formula; $p<0.01$ and ${ }^{i} p<0.05$ as compared with AR single formula.

Table 14. Femoral and Tibial AC with SM PARP-Immunolabeled Cell Numbers in Sham-Operated or OA Rats

\begin{tabular}{|c|c|c|c|c|}
\hline \multirow[b]{2}{*}{ Groups } & \multirow[t]{2}{*}{ Items } & \multicolumn{3}{|c|}{ PARP-immunolabeled cell numbers } \\
\hline & & Femoral AC & Tibial AC & SM \\
\hline \multicolumn{5}{|l|}{ Controls } \\
\hline Sham & & $67.80 \pm 31.11$ & $64.70 \pm 16.57$ & $12.40 \pm 11.53$ \\
\hline $\mathrm{OA}$ & & $509.60 \pm 123.35^{\mathrm{a}}$ & $567.70 \pm 81.92^{\mathrm{a}}$ & $561.00 \pm 158.22^{\mathrm{a}}$ \\
\hline Diclofenac & & $153.10 \pm 28.11^{\mathrm{ab}}$ & $156.30 \pm 53.82^{a b}$ & $110.30 \pm 28.44^{a b}$ \\
\hline \multicolumn{5}{|l|}{ Single formula } \\
\hline PCP & & $205.20 \pm 40.92^{\mathrm{ab}}$ & $235.70 \pm 46.80^{\mathrm{ab}}$ & $214.30 \pm 43.73^{a b}$ \\
\hline $\mathrm{EC}$ & & $293.40 \pm 68.78^{\mathrm{ab}}$ & $255.90 \pm 36.56^{\mathrm{ab}}$ & $281.70 \pm 68.85^{a b}$ \\
\hline $\mathrm{AR}$ & & $266.50 \pm 41.44^{\mathrm{ab}}$ & $318.30 \pm 55.25^{\mathrm{ab}}$ & $345.20 \pm 67.85^{a b}$ \\
\hline \multicolumn{5}{|c|}{ Mixed formula - PCP and EC:AR } \\
\hline $1: 1$ & & $152.90 \pm 22.91$ abceg & $162.80 \pm 54.63$ abceg & $143.30 \pm 26.93$ abceg \\
\hline $1: 2$ & & $155.70 \pm 30.20^{\text {abceg }}$ & $158.30 \pm 30.85^{\text {abceg }}$ & $151.80 \pm 33.86^{\text {abceg }}$ \\
\hline $1: 4$ & & $204.50 \pm 23.02$ abeg & $194.40 \pm 31.94$ abdeg & $189.60 \pm 24.10^{\text {abeg }}$ \\
\hline $1: 6$ & & $254.70 \pm 79.35^{a b}$ & $286.60 \pm 96.75^{a b}$ & $287.60 \pm 59.21 \mathrm{abc}$ \\
\hline $1: 8$ & & $288.30 \pm 109.10^{a b}$ & $296.30 \pm 163.33^{\mathrm{ab}}$ & $289.50 \pm 97.76^{\mathrm{abd}}$ \\
\hline $2: 1$ & & $137.90 \pm 38.27^{\text {abceg }}$ & $137.70 \pm 45.70$ abceg & $110.90 \pm 23.97$ abceg \\
\hline $4: 1$ & & $112.00 \pm 22.38$ abceg & $119.60 \pm 22.53$ abceg & $98.10 \pm 21.03$ abceg \\
\hline $6: 1$ & & $216.70 \pm 44.44^{\mathrm{abfh}}$ & $230.90 \pm 101.22$ abh & $201.50 \pm 51.31$ abeg \\
\hline $8: 1$ & & $297.40 \pm 112.71^{a b}$ & $266.90 \pm 115.36^{\mathrm{ab}}$ & $257.80 \pm 76.87^{\text {abh }}$ \\
\hline
\end{tabular}

Values are expressed mean \pm SD of 10 rats, cells $/ \mathrm{mm}^{2}$. AR = Aqueous extracts of Achyranthis Radix, OA = Osteoarthritis; EC = Aqueous extracts of Eucommiae Cortex, PCP = Pomegranate Concentration Powder; AC = Articular cartilage; SM = Synovial membrane; PARP $=$ Cleaved poly(ADP-ribose) polymerase ${ }^{a} p<0.01$ as compared with sham control; ${ }^{b} p<0.01$ as compared with $0 A$ control; ${ }^{\mathrm{c}} p<0.01$ and ${ }^{d} p<0.05$ as compared with PCP single formula; ${ }^{\mathrm{e}} p<0.01$ and ${ }^{\dagger} p<0.05$ as compared with EC single formula; ${ }^{g} p<0.01$ and ${ }^{h}$ $p<0.05$ as compared with AR single formula. 
Table 15. Femoral and Tibial AC with SM COX-2-Immunostained Cell Numbers in Sham-Operated or OA Rats

\begin{tabular}{|c|c|c|c|}
\hline \multirow[b]{2}{*}{ Groups } & \multicolumn{3}{|c|}{ COX-2-immunostained cell numbers } \\
\hline & Femoral AC & Tibial AC & SM \\
\hline \multicolumn{4}{|l|}{ Controls } \\
\hline Sham & $34.40 \pm 10.96$ & $54.80 \pm 19.79$ & $6.40 \pm 3.44$ \\
\hline OA & $359.70 \pm 70.96^{\mathrm{a}}$ & $327.10 \pm 59.45^{\text {a }}$ & $877.40 \pm 165.90^{\mathrm{a}}$ \\
\hline Diclofenac & $134.40 \pm 46.25^{\mathrm{ab}}$ & $152.40 \pm 47.88^{\mathrm{ab}}$ & $63.70 \pm 25.09$ ab \\
\hline \multicolumn{4}{|l|}{ Single formula } \\
\hline PCP & $237.10 \pm 33.72^{a b}$ & $234.40 \pm 39.30^{\mathrm{ab}}$ & $112.70 \pm 26.59^{\mathrm{ab}}$ \\
\hline $\mathrm{EC}$ & $278.70 \pm 33.66^{\mathrm{ab}}$ & $256.40 \pm 46.86^{\mathrm{ab}}$ & $236.10 \pm 40.46^{\mathrm{ab}}$ \\
\hline $\mathrm{AR}$ & $303.10 \pm 26.11$ ac & $257.50 \pm 32.15^{\mathrm{ab}}$ & $258.20 \pm 69.60^{\mathrm{ab}}$ \\
\hline \multicolumn{4}{|c|}{ Mixed formula - PCP and EC:AR } \\
\hline $1: 1$ & $175.50 \pm 17.32$ abdfh & $158.20 \pm 31.84^{\text {abdfh }}$ & $68.40 \pm 13.87^{\text {abdfh }}$ \\
\hline $1: 2$ & $178.00 \pm 20.19^{\text {abdfh }}$ & $163.20 \pm 14.74$ abdfh & $79.00 \pm 29.97$ abefh \\
\hline $1: 4$ & $193.60 \pm 18.45^{\text {abdfh }}$ & $173.40 \pm 22.09$ abdfh & $81.70 \pm 21.93$ abefh \\
\hline $1: 6$ & $236.40 \pm 48.38$ abgh & $222.10 \pm 39.32$ abi & $123.50 \pm 51.64$ abgi \\
\hline $1: 8$ & $247.00 \pm 42.89$ abh & $252.40 \pm 46.77^{\mathrm{ab}}$ & $129.50 \pm 47.35^{\text {abgi }}$ \\
\hline $2: 1$ & $116.60 \pm 33.54$ abdfh & $144.40 \pm 16.82^{\text {abdfh }}$ & $51.00 \pm 15.25^{\text {abdfh }}$ \\
\hline $4: 1$ & $94.20 \pm 19.76^{\text {abdfh }}$ & $110.50 \pm 17.21$ abdfh & $31.00 \pm 13.04$ abdfh \\
\hline $6: 1$ & $253.50 \pm 43.61$ & $221.10 \pm 49.04^{\mathrm{ab}}$ & $104.30 \pm 43.73^{\text {abfh }}$ \\
\hline $8: 1$ & $259.30 \pm 70.64$ & $237.60 \pm 85.08^{\mathrm{ac}}$ & $137.40 \pm 50.87^{\text {abfh }}$ \\
\hline
\end{tabular}

Values are expressed mean $\pm \mathrm{SD}$ of 10 rats, cells $/ \mathrm{mm}^{2}$. AR $=$ Aqueous extracts of Achyranthis Radix, OA = Osteoarthritis; EC $=$ Aqueous extracts of Eucommiae Cortex, $\mathrm{PCP}=$ Pomegranate Concentration Powder; $\mathrm{AC}=$ Articular cartilage; $\mathrm{SM}=$ Synovial membrane; $\mathrm{COX}$ $=$ Cyclooxygenase ${ }^{a} p<0.01$ as compared with sham control; ${ }^{b} p<0.01$ and ${ }^{c} p<0.05$ as compared with $0 A$ control; ${ }^{d} p<0.01$ and ${ }^{e} p<0.05$ as compared with PCP single formula; ${ }^{\dagger} p<0.01$ and ${ }^{9} p<0.05$ as compared with EC single formula; ${ }^{h} p<0.01$ and ${ }^{i} p<0.05$ as compared with AR single formula.

Table 16. Femoral and Tibial AC with SM TNF- $\alpha-$ Immunopositive Cell Numbers in Sham-Operated or OA Rats

\begin{tabular}{|c|c|c|c|}
\hline \multirow[b]{2}{*}{ Groups } & \multicolumn{3}{|c|}{ TNF-a-immunopositive cell numbers } \\
\hline & Femoral AC & Tibial AC & SM \\
\hline \multicolumn{4}{|l|}{ Controls } \\
\hline Sham & $34.70 \pm 19.18$ & $52.10 \pm 14.43$ & $4.10 \pm 2.28$ \\
\hline $\mathrm{OA}$ & $328.60 \pm 56.42^{a}$ & $305.20 \pm 38.88^{a}$ & $326.70 \pm 80.00^{\mathrm{a}}$ \\
\hline Diclofenac & $148.70 \pm 48.90^{\mathrm{ac}}$ & $121.00 \pm 35.00^{\mathrm{ac}}$ & $35.20 \pm 19.66^{\mathrm{ac}}$ \\
\hline \multicolumn{4}{|l|}{ Single formula } \\
\hline PCP & $210.80 \pm 43.30^{\mathrm{ac}}$ & $209.70 \pm 34.42 \mathrm{ac}$ & $71.30 \pm 15.94^{\mathrm{ac}}$ \\
\hline EC & $241.30 \pm 33.32 \mathrm{ac}$ & $228.70 \pm 42.92{ }^{\mathrm{ac}}$ & $97.50 \pm 23.42$ ac \\
\hline $\mathrm{AR}$ & $249.70 \pm 29.54^{\text {ac }}$ & $238.00 \pm 31.57^{\mathrm{ac}}$ & $101.30 \pm 25.88^{\mathrm{ac}}$ \\
\hline \multicolumn{4}{|c|}{ Mixed formula - PCP and EC:AR } \\
\hline $1: 1$ & $128.60 \pm 32.18$ acdfh & $148.80 \pm 30.05^{\text {acdef }}$ & $27.40 \pm 7.06^{\text {acdfh }}$ \\
\hline $1: 2$ & $147.40 \pm 26.53$ acdfh & $157.90 \pm 21.63$ acdef & $28.60 \pm 9.11$ acdfh \\
\hline $1: 4$ & $156.00 \pm 30.34$ acdfh & $150.60 \pm 19.75$ acdef & $36.20 \pm 9.68$ acdfh \\
\hline $1: 6$ & $217.00 \pm 32.39$ aci & $214.20 \pm 38.14^{\text {ac }}$ & $83.70 \pm 21.97$ ac \\
\hline $1: 8$ & $220.70 \pm 47.50^{\mathrm{ac}}$ & $215.90 \pm 42.92^{\mathrm{ac}}$ & $89.10 \pm 23.00^{\mathrm{ac}}$ \\
\hline $2: 1$ & $89.60 \pm 26.98^{\text {acdfh }}$ & $105.90 \pm 22.94$ acdef & $23.10 \pm 9.84$ acdfh \\
\hline $4: 1$ & $68.30 \pm 13.01$ acdfh & $81.60 \pm 23.48$ bcdef & $11.90 \pm 4.63$ acdfh \\
\hline $6: 1$ & $229.20 \pm 44.70^{\mathrm{ac}}$ & $189.20 \pm 32.52$ acef & $70.90 \pm 17.77^{\text {acgh }}$ \\
\hline $8: 1$ & $243.30 \pm 33.70$ ace & $208.10 \pm 47.14^{\mathrm{acg}}$ & $77.20 \pm 14.02^{\text {acgi }}$ \\
\hline
\end{tabular}

Values are expressed mean $\pm \mathrm{SD}$ of 10 rats, cells $/ \mathrm{mm}^{2}$. AR $=$ Aqueous extracts of Achyranthis Radix, OA = Osteoarthritis; EC = Aqueous extracts of Eucommiae Cortex, $\mathrm{PCP}=$ Pomegranate Concentration Powder; $\mathrm{AC}=$ Articular cartilage; $\mathrm{SM}=$ Synovial membrane; TNF $=$ Tumor necrosis factor. ${ }^{a} p<0.01$ and ${ }^{b} p<0.05$ as compared with sham control; ${ }^{c} p<0.01$ as compared with $0 A$ control; ${ }^{d} p<0.01$ and ${ }^{\mathrm{e}} p<0.05$ as compared with PCP single formula; ${ }^{\dagger} p<0.01$ and ${ }^{9} p<0.05$ as compared with EC single formula; ${ }^{h} p<0.01$ and $p<0.05$ as compared with AR single formula. 
and leukotriene as one of potent inflammatory mediator by increase of COX-2 and 5-LPO activities coordination with interleukin (IL)-1 and TNF-a other potent inflammatory mediators. These acute inflammatory processes induced edematous changes on the surround tissues, and the thicknesses of affected joints were marked increased with abnormal bone growth and painful osteophytes, which were frequently encounted in the patients suffering from osteoarthritis $^{16,44-46)}$. In the present study, OA control rats showed significant increases of knee thicknesses, decreases of the femur and tibia $\mathrm{AC}$ thicknesses, along significant increases of COX-2- and TNF- $a$ -immunolabeled cell numbers at inspections of histopathology. In addition, OA control rats also showed noticeable and significant increases of the COX-2- and TNF-a-immunopositive cells on the SM, with marked elevations of $\mathrm{PGE}_{2}$ levels and 5-LPO activities on the femur and tibia AC with SM, respectively. However, these surgically-induced OA related inflammatory signs in OA rats were significantly inhibited by 28 days of continuous treatment of PCP, EC and AR single formulas, and also by all nine types of PCP and EC:AR mixed formulas in this study. Especially, PCP and EC:AR 4:1, 2:1 and 1:1 mixed formula treated OA rats constantly showed significantly more favorable anti-inflammatory activities as compared with those of single formula of PCP, EC and AR treated rats.

Important enzymes involved in deconstruction of chondrocyte and bony tissue, are proteolytic enzymes, MMPs, and they were inhibited by tissue inhibitor of metalloproteinases system at normal conditions47). Since MMPs act as protease that degraded the ECM, mainly $\mathrm{PGs}^{48)}$, they have been regarded as a valuable treatment target in osteoarthritis $^{6,49)}$. As results of the present study, dramatic increases of MMP-2 and MMP-9 activities were observed on the femur and tibia $\mathrm{AC}$ with SM of $\mathrm{OA}$ control rats, however, these $\mathrm{OA}$ related increases of MMP-2 and MMP-9 activities were significantly inhibited by 28 days of continuous treatment of PCP, EC and AR single formulas, and also by all nine types of PCP and EC:AR mixed formulas in this study. Especially, PCP and EC:AR 4:1, 2:1 and 1:1 mixed formula treated OA rats constantly showed significantly more favorable inhibitory effects against MMP-2 and MMP-9 activities on the femur and tibia $\mathrm{AC}$ with $\mathrm{SM}$ as compared with those of single formula of PCP, EC and $\mathrm{AR}$ treated rats.

Fibrosis occurs during the development of OA due to chronic inflammation, and it subsequently limits joint motion. As stiff joints are a prominent symptom of $\mathrm{OA}$, the maximum extension angle of the joint is used to evaluate joint stiffness, with $0^{\circ}$ as maximum extension, i.e., knee function is better with lower values ${ }^{33-37)}$. Noticeable and significant increases of the maximum extension angles in induced knees, detected in OA control rats of this experiment indicated that $\mathrm{OA}$ was well induced by proper surgical processes. Marked hypertrophy and hyperplasia of SM tissue have been observed in animals with $\mathrm{OA}$ as a result of SM tissue fibrosis-related joint stiffness ${ }^{50,51)}$, and also in OA control rats of present study. However, these OA related increases of the maximum extension angles in induced knees, hypertrophic changes on the SM lining epithelium were significantly inhibited by 28 days of continuous treatment of PCP, EC and AR single formulas, and also by all nine types of PCP and EC:AR mixed formulas in this experiment. Especially, PCP and EC:AR 4:1, 2:1 and 1:1 mixed formula treated $\mathrm{OA}$ rats constantly showed significantly more favorable inhibitory effects against knee stiffness and SM proliferations as compared with those of single formula of PCP, EC and AR treated rats.

Our results show that all nine types of the PCP and EC:AR mixed formulas significantly inhibited OA-related increases in femoral and tibial $\mathrm{AC}$ Mankin scores and decreased cartilage thickness. 
Notably, the PCP- and EC:AR 4:1, 2:1, and 1:1 mixed-formula-treated $\mathrm{OA}$ rats had significantly lower femoral and tibial Mankin scores and higher femoral and tibial $\mathrm{AC}$ thicknesses than did single-formula PCP-, EC-, and AR-treated rats. The Mankin scoring system is widely used for histopathological evaluations. Higher scores indicate higher levels of OA. It can detect articular cartilage injuries based on cartilage surface damages, chondrocyte numbers, clone formations and statin intensity to Safranin $\mathrm{O}^{33-37,52)}$.

Apoptosis occurs through two pathways, an extrinsic pathway involving the interaction of death ligands with their respective cell surface receptors and an intrinsic pathway that is initiated by insults that damage the DNA, such as ultraviolet light and chemotherapeutic agents. Both pathways eventually result in mitochondrial damage with release of cytochrome $\mathrm{c}$ and downstream activation of caspases, such as caspase-3. Activation of other downstream caspases results in cleavage of cellular proteins, such as PARP, cytokeratin 18, and other caspases, that lead to the morphologic and biochemical changes of apoptosis $^{41,53)}$. PARP is a nuclear DNA-binding protein that functions in DNA base excision repair ${ }^{54)}$. PARP cleavage results in a decreased enzymatic repair function and contributes to the progression of apoptosis, although PARP cleavage is not absolutely necessary for apoptosis to proceed ${ }^{55)}$. The inhibition of apoptosis, the immunoreactivities of PARP is considered in a useful strategy for preventing from various organ damages ${ }^{56)}$ including OA34,57,58). Therefore, we used PARP as apoptotic marker to observe the protective effects of test substances on the articular cartilages and also on the SM, respectively. In the present study, marked increases of PARP-immunoreactive cells, indicating apoptosis, were demonstrated on the femur and tibia $\mathrm{AC}$ with $\mathrm{SM}$ of OA control rats, however, these OA related increases of PARP-immunolabeled cells were significantly inhibited by 28 days of continuous treatment of PCP, EC and AR single formulas, and also by all nine types of PCP and EC:AR mixed formulas in this study. Especially, PCP and EC:AR 4:1, 2:1, 1:1 and 1:2 mixed formula treated OA rats constantly showed significantly more favorable inhibitory effects against $\mathrm{OA}$ related increases of apoptosis on the femur and tibia $\mathrm{AC}$ with $\mathrm{SM}$ as compared with those of single formula of PCP, EC and $\mathrm{AR}$ treated rats.

Among the methods for the detection of cell proliferation in histological sections, immunohistochemistry for $\mathrm{BrdU}$ are the most preferable ones ${ }^{59,60)}$. BrdU staining was easier to read and seeded to reflect cell proliferations more specifically than other staining ${ }^{40)}$, and also have been prevalently used to detect cell proliferation in $\mathrm{OA}$ animals ${ }^{33-36}$. Cells contain $\mathrm{BrUd}$ means proliferated or proliferating cells ${ }^{33-36,60)}$. In this experiment, marked decreases of BrdU-immunoreactive cells were demonstrated on the femur and tibia $\mathrm{AC}$ of OA control rats, indicating classic OA related chondrocyte proliferation inhibitory histopathological signs. On the contrary, significant increases of BrdU-positive cells were observed on the SM of OA control as compared to those of sham control rats, indicating $\mathrm{OA}$ related hyperplasia and fibrotic changes on the SM of the present study. Diclofenac treated rats showed noticeable decreases of BrdU-immunoreactive cells on the SM, may be related its potent anti-inflammatory activity, it did not influenced on the femur and tibia $\mathrm{AC}$ BrdU-immunolabeled cell numbers as compared with OA control rats, respectively. However, significant increases of BrdU-immunostained cells on the both femur and tibia AC, indicating chondrocyte proliferations, and decreases in the SM indicating possible anti-inflammatory activities were observed by 28 days of continuous treatment of PCP, EC and AR single formulas, and also by all nine types of PCP and EC:AR mixed formulas in this study. Especially, PCP and EC:AR 4:1, 2:1 and 1:1 mixed formula treated $\mathrm{OA}$ rats constantly showed more 
favorable increases of BrdU-immunoreactive cells on the femur and tibia $\mathrm{AC}$, and decreases in the $\mathrm{SM}$ as compared with those of single formula of PCP, EC and $\mathrm{AR}$ treated rats.

The ECM of articular cartilage is composed mainly of collagen and GAGs, PG - aggrecan and $\mathrm{SOX}^{5,6,39)}$. OA is characterized by loss of articular cartilage components, mainly PGs, leading to tissue destruction and hypocellularity, eventually resulting in loss of joint function ${ }^{7)}$. It has been believed that degradations of ECM such as collagen, aggrecan and SOX9 from the results of inflammation related chondrocyte deaths and damages are involved in the deterioration of the homeostasis and articular functional limitations in $\mathrm{OA}^{61)}$. SOX9 is a transcription factor essential for chondrogenic differentiation ${ }^{62}$, and aggrecan and collagen is a key component of the ECM of healthy cartilage ${ }^{39)}$. Prevention of these ECM degradations, therefore, has been treated as a valuable anti-OA target for various treatments ${ }^{38,39,63)}$. In the present study, significant decreases of the ECM related chondrogenic mRNA expressions collagen type II, aggrecan and SOX9 mRNA expressions were demonstrated in the femur and tibia AC OA control as compared with sham control rats. In SMs of OA control rats, significant decreases of aggrecan and SOX9 mRNA expressions were also noticed as compared with sham control rats, but mRNA expressions of collagen type II on the SM were significantly increased in $\mathrm{OA}$ control rats as compared with sham control rats, in this experiment. These increases of collagen type II mRNA expressions on the SM, may be results from focal fibrosis and stiffness, a classic signs of $\mathrm{OA}^{33-37)}$. However, these OA related decreases of chondrogenic mRNA expressions, and increases collagen type II mRNA expressions on the SM were significantly inhibited by 28 days of continuous treatment of PCP, $\mathrm{EC}$ and AR single formulas, and also by all nine types of PCP and EC:AR mixed formulas, respectively. Once again and finally, PCP and
EC:AR 4:1, 2:1 and 1:1 mixed formula treated OA rats constantly showed significantly more favorable inhibitory effects against $\mathrm{OA}$ related chondrogenic mRNA expression changes on the femur and tibia $\mathrm{AC}$ with $\mathrm{SM}$ as compared with those of single formula of PCP, EC and AR treated rats.

\section{Conclusions}

Taken together, we demonstrated that an appropriate mixture consisting of PCP and EC:AR synergistically increased the anti-OA effects of each single formula of PCP, EC and AR in rats with surgically induced $\mathrm{OA}$, through synergic anti -inflammatory and chondrogenic activities. The PCP and EC:AR (2:1, 4:1, and 1:1) mixtures enhanced anti-OA effects, suggesting that this mixture may be used as a natural alternative to treat OA.

\section{Acknowledgments}

This research was supported by the Foundation of Agri. Tech. Commericalization \& Transfer(FACT) through the $\mathrm{R} \& \mathrm{D}$ Results Commericalization Support Project(NO. PJ011566) on 2015.

\section{References}

1. Dougados M, Nguyen M, Berdah L, Mazieres $\mathrm{B}$, Vignon E, Lequesne $\mathrm{M}$, et al. Evaluation of the structure-modifying effects of diacerein in hip osteoarthritis: ECHODIAH, a three-year, placebo-controlled trial. Evaluation of the Chondromodulating Effect of Diacerein in OA of the Hip. Arthritis and rheumatism 2001; 44(11):2539-47.

2. Goldring MB, Goldring SR. Osteoarthritis. Journal of cellular physiology. 2007;213(3): 626-34.

3. Pavelká K, Gatterová J, Olejarová M, Machacek S, Giacovelli G, Rovati LC. Glucosamine sulfate 
use and delay of progression of knee osteoarthritis: a 3-year, randomized, placebo -controlled, double-blind study. Archives of internal medicine. 2002;162(18):2113-23.

4. Fiorito S, Magrini L, Adrey J, Mailhé D, Brouty-Boyé D. Inflammatory status and cartilage regenerative potential of synovial fibroblasts from patients with osteoarthritis and chondropathy. Rheumatology (Oxford, England). 2005;44(2): 164-71.

5. Qin J, Liu YS, Liu J, Li J, Tan Y, Li XJ, et al. Effect of Angelica sinensis Polysaccharides on Osteoarthritis In Vivo and In Vitro: A Possible Mechanism to Promote Proteoglycans Synthesis. Evid. Based Complement. Alternat. Med. 2013; 2013:794761.

6. Na JY, Song KB, Kim SH, Kwon YB, Kim DG, Lee JK, et al. Effects of HPL-04 on degenerative osteoarthritis. J. Korean Soc. Food Sci. Nutr. 2014;43(1):30-9.

7. Felson DT, Zhang Y. An update on the epidemiology of knee and hip osteoarthritis with a view to prevention. Arthritis Rheum. 1998; 41(8):1343-55.

8. Goldring MB, Fukuo K, Birkhead JR, Dudek E, Sandell LJ. Transcriptional suppression by interleukin-1 and interferon-gamma of type II collagen gene expression in human chondrocytes.

J. Cell Biochem. 1994;54(1):85-99.

9. van de Loo FA, Joosten LA, van Lent PL, Arntz OJ, van den Berg WB. Role of interleukin-1, tumor necrosis factor a, and interleukin-6 in cartilage proteoglycan metabolism and destruction. Effect of in situ blocking in murine antigenand zymosan-induced arthritis. Arthritis Rheum. 1995;38(2):164-72.

10. Berenbaum F, Jacques C, Thomas G, Corvol MT, Bereziat G, Masliah J. Synergistic effect of interleukin-1b and tumor necrosis factor alpha on $\mathrm{PGE}_{2}$ production by articular chondrocytes does not involve $\mathrm{PLA}_{2}$ stimulation. Exp. Cell
Res. 1996;222(2):379-84.

11. Grabowski PS, Macpherson H, Ralston SH. Nitric oxide production in cells derived from the human joint. Br. J. Rheumatol. 1996;35(3): 207-12.

12. Stefanovic-Racic M, Morales TI, Taskiran D, McIntyre LA, Evans $\mathrm{CH}$. The role of nitric oxide in proteoglycan turnover by bovine articular cartilage organ cultures. J. Immunol. 1996;156(3):1213-20.

13. Koolpe M, Pearson D, Benton HP. Expression of both $P_{1}$ and $P_{2}$ purine receptor genes by human articular chondrocytes and profile of ligand-mediated prostaglandin $\mathrm{E}_{2}$ release. Arthritis Rheum. 1999;42(2):258-67.

14. Felson DT, Neogi T. Osteoarthritis: is it a disease of cartilage or of bone? Arthritis and rheumatism. 2004;50(2):341-4.

15. Tamura T, Ohmori K. Rhein, an active metabolite of diacerein, suppresses the interleukin-la -induced proteoglycan degradation in cultured rabbit articular chondrocytes. Jpn. J. Pharmacol. 2001;85(1):101-4.

16. Nam DE, Kim OK, Shim TJ, Kim JH, Lee JM. Effect of Boswellia serrata extracts on degenerative osteoarthritis in vitro and in vivo models. J. Korean Soc. Food Sci. Nutr. 2014; 43(5):631-40.

17. Langley P. Why a pomegranate? BMJ (Clinical research ed.). 2000;321(7269):1153-4.

18. Gil MI, Tomás-Barberán FA, Hess-Pierce B, Holcroft DM, Kader AA. Antioxidant activity of pomegranate juice and its relationship with phenolic composition and processing. J. Agric. Food Chem. 2000;48(10):4581-9.

19. Noda $Y$, Kaneyuki T, Mori A, Packer L. Antioxidant activities of pomegranate fruit extract and its anthocyanidins: delphinidin, cyanidin, and pelargonidin. J. Agric. Food Chem. 2002;50(1):166-71.

20. Singh RP, Chidambara Murthy KN, Jayaprakasha 
GK. Studies on the antioxidant activity of pomegranate (Punica granatum) peel and seed extracts using in vitro models. J. Agric. Food Chem. 2002;50(1):81-6.

21. Ahmed S, Wang N, Hafeez BB, Cheruvu VK, Haqqi TM. Punica granatum L. extract inhibits IL-1b-induced expression of matrix metalloproteinases by inhibiting the activation of MAP kinases and NF-kB in human chondrocytes in vitro. J. Nutr. 2005;135(9):2096-102.

22. Shukla M, Gupta K, Rasheed Z, Khan KA, Haqqi TM. Bioavailable constituents/metabolites of pomegranate (Punica granatum L) preferentially inhibit COX2 activity ex vivo and IL-1beta -induced PGE2 production in human chondrocytes in vitro. J. Inflamm. 2008;5:9.

23. Hadipour-Jahromy M, Mozaffari-Kermani R. Chondroprotective effects of pomegranate juice on monoiodoacetate-induced osteoarthritis of the knee joint of mice. Phytother. Res. 2010;24(2): 182-5.

24. Rasheed Z, Akhtar N, Haqqi TM. Pomegranate extract inhibits the interleukin-1b-induced activation of MKK-3, p38a-MAPK and transcription factor RUNX-2 in human osteoarthritis chondrocytes. Arthritis Res. Ther. 2010;12(5):R195.

25. Hsieh CL, Yen GC. Antioxidant actions of du-zhong (Eucommia ulmoides Oliv.) toward oxidative damage in biomolecules. Life Sci. 2000;66(15):1387-400.

26. Kwan CY, Chen CX, Deyama T, Nishibe S. Endothelium-dependent vasorelaxant effects of the aqueous extracts of the Eucommia ulmoides Oliv. leaf and bark: implications on their antihypertensive action. Vascul. Pharmacol. 2003;40(5):229-35.

27. Zhao Y, Li Y, Wang $\mathrm{X}$, Sun $\mathrm{W}$. The experimental study of Cortex Eucommiae on meridian tropsim: the distribution study of aucubin in rat tissues. J. Pharm. Biomed. Anal. 2008;46(2):368-73.
28. Eum HA, Lee WY, Kim SH, Kim JY, Park SW, Lee JS, et al. Anti-inflammatory activity of CML-1: an herbal formulation. Am. J. Chin. Med. 2005;33(1):29-40.

29. Lee SY, Kwon HK, Lee SM. SHINBARO, a new herbal medicine with multifunctional mechanism for joint disease: first therapeutic application for the treatment of osteoarthritis. Arch. Pharm. Res. 2011;34(11):1773-7.

30. Li J, Li HJ, Li P, Qi H, Simultaneous qualitation and quantification of four phytoecdysones in Radix Achyranthis Bidentatae by high-performance liquid chromatography with diode array detection. Biomed. Chromatogr. 2007;21(8): 823-8.

31. Yu F, Li X, Cai L, Li H, Chen J, Wong X, et al. Achyranthes bidentata polysaccharides induce chondrocyte proliferation via the promotion of the $\mathrm{G}_{1} / \mathrm{S}$ cell cycle transition. Mol. Med. Rep. 2013;7(3):935-40.

32. Weng X, Lin P, Liu F, Chen J, Li H, Huang L, et al. Achyranthes bidentata polysaccharides activate the Wnt/b-catenin signaling pathway to promote chondrocyte proliferation. Int. J. Mol. Med. 2014;34(4):1045-50.

33. Kim JW, Cho HR, Ku S., Efficacy test of Polycan, a beta-glucan originated from Aureobasidium pullulans SM-2001, on anterior cruciate ligament transection and partial medial meniscectomy-induced-osteoarthritis rats. Journal of microbiology and biotechnology. 2012;22(2): 274-82.

34. Kang SJ, Kim JW, Kim KY, Ku SK, Lee YJ. Protective effects of calcium gluconate on osteoarthritis induced by anterior cruciate ligament transection and partial medial meniscectomy in Sprague-Dawley rats. Journal of orthopaedic surgery and research. 2014; 9(1):14.

35. Moon $\mathrm{CH}$, Kwon $\mathrm{O}$, Woo $\mathrm{CH}$, Ahn HD, Kwon YS, Park SJ, et al. Therapeutic effect of irradiation of magnetic infrared laser on 
osteoarthritis rat model. Photochemistry and photobiology. 2014;90(5):1150-9.

36. Choi JS, Shin HS, Kim KY, Ku SK, Choi IS, Kim JW. Effect of Polycalcium, a mixture of Polycan and calcium lactate-gluconate in a 1:9 weight ratio, on rats with surgery-induced osteoarthritis. Exp. Ther. Med. 2015;9(5):178090.

37. Rezende MU, Gurgel HM, Vilaça Junior PR, Kuroba RK, Lopes AS, Phillipi RZ, et al. Diacerhein versus glucosamine in a rat model of osteoarthritis. Clinics (Sao Paulo, Brazil). 2006; 61(5):461-6.

38. Rai MF, Graeve T, Twardziok S, Schmidt MF. Evidence for regulated interleukin-4 expression in chondrocyte-scaffolds under in vitro inflammatory conditions. PloS one. 2011;6(10):e25749.

39. Innes JF, Gordon $\mathrm{C}$, Vaughan-Thomas $\mathrm{A}$, Rhodes NP, Clegg PD. Evaluation of cartilage, synovium and adipose tissue as cellular sources for osteochondral repair. Veterinary journal (London, England : 1997). 2013;197(3):619-24.

40. Hwang YI, Yoo YB, Baik SH. Comparative study of rat thyroid regeneration using PCNA and BrdU immunohistochemistry. Korean J Anat. 2000;33(2):247-54.

41. Barrett KL, Willingham JM, Garvin AJ, Willingham MC. Advances in cytochemical methods for detection of apoptosis. The journal of histochemistry and cytochemistry : official journal of the Histochemistry Society. 2001; 49(7):821-32.

42. Hwangbo M, Jung JY, Ki SH, Park SM, Jegal $\mathrm{KH}$, Cho IJ, et al. U-Bang-Haequi Tang: A Herbal Prescription that Prevents Acute Inflammation through Inhibition of NF-kB -Mediated Inducible Nitric Oxide Synthase. Evidence-based complementary and alternative medicine : eCAM. 2014;2014:542825.

43. Lee CW, Park SM, Kim YS, Jegal KH, Lee JR, Cho IJ, et al. Biomolecular evidence of anti-inflammatory effects by Clematis mandshurica Ruprecht root extract in rodent cells. Journal of ethnopharmacology. 2014; 155(2):1141-55.

44. Sailer ER, Schweizer S, Boden SE, Ammon HP, Safayhi H. Characterization of an acetyl-11 -keto-b-boswellic acid and arachidonate-binding regulatory site of 5-lipoxygenase using photoaffinity labeling. Eur. J. Biochem. 1998; 256(2):364-8.

45. Guo JS, Ou L, Zhou J, Wang XJ, Guo X. Impact on the model of rat osteoarthritis of jingu tablet. Zhongguo Zhong yao za zhi = Zhongguo zhongyao zazhi $=$ China journal of Chinese materia medica. 2006;31(3):232-5.

46. Hardy MM, Seibert K, Manning PT, Currie MG, Woerner BM, Edwards D, et al. Cyclooxygenase 2-dependent prostaglandin $\mathrm{E}_{2}$ modulates cartilage proteoglycan degradation in human osteoarthritis explants. Arthritis Rheum. 2002;46(7):1789-803.

47. Bresnihan B. Pathogenesis of joint damage in rheumatoid arthritis. J. Rheumatol. 1999;26(3): 717-9.

48. Nagase H, Woessner JF, Jr. Matrix metalloproteinases. J. Biol. Chem. 1999;274(31):21491-4.

49. Halliwell B. Oral inflammation and reactive species: a missed opportunity? Oral Dis. 2000; 6(3):136-7.

50. Permuy M, Guede D, López-Peña M, Muñoz F, Caeiro JR, González-Cantalapiedra A. Effects of diacerein on cartilage and subchondral bone in early stages of osteoarthritis in a rabbit model. BMC veterinary research. 2015;11:143.

51. Permuy M, Guede D, López-Peña M, Muñoz F, Caeiro JR, González-Cantalapiedra A. Comparison of various SYSADOA for the osteoarthritis treatment: an experimental study in rabbits. BMC musculoskeletal disorders. 2015;16:120.

52. Armstrong S, Read R, Ghosh P. The effects of intraarticular hyaluronan on cartilage and 
subchondral bone changes in an ovine model of early osteoarthritis. The Journal of rheumatology. 1994;21(4):680-8.

53. Nuñez $G$, Benedict $M A, H u ~ Y$, Inohara $N$. Caspases: the proteases of the apoptotic pathway. Oncogene. 1998;17(25):3237-45.

54. Trucco C, Oliver FJ, de Murcia G, Menissier-de Murcia J. DNA repair defect in poly (ADP-ribose) polymerase-deficient cell lines. Nucleic acids research. 1998;26(11):2644-9.

55. Smulson ME, Pang D, Jung M, Dimtchev A, Chasovskikh S, Spoonde A, et al. Irreversible binding of poly(ADP)ribose polymerase cleavage product to DNA ends revealed by atomic force microscopy: possible role in apoptosis. Cancer research. 1998;58(16):3495-8.

56. Cole KK, Perez-Polo JR. Poly(ADP-ribose) polymerase inhibition prevents both apoptotic -like delayed neuronal death and necrosis after $\mathrm{H}_{2} \mathrm{O}_{2}$ injury. Journal of neurochemistry. 2002; 82(1):19-29.

57. Cheng W, Wu D, Zuo Q, Wang Z, Fan W. Ginsenoside Rb1 prevents interleukin-1 beta induced inflammation and apoptosis in human articular chondrocytes. International orthopaedics. 2013;37(10):2065-70.

58. Xue H, Tu Y, Ma T, Liu X, Wen T, Cai M, et al. Lactoferrin Inhibits IL-1b-Induced Chondrocyte Apoptosis Through AKT1-Induced CREB1 Activation. Cellular physiology and biochemistry : international journal of experimental cellular physiology, biochemistry, and pharmacology.
2015;36(6):2456-65.

59. Ganey T, Libera J, Moos V, Alasevic O, Fritsch KG, Meisel HJ, et al. Disc chondrocyte transplantation in a canine model: a treatment for degenerated or damaged intervertebral disc. Spine. 2003;28(23):2609-20.

60. Moore EE, Bendele AM, Thompson DL, Littau A, Waggie KS, Reardon B, et al. Fibroblast growth factor-18 stimulates chondrogenesis and cartilage repair in a rat model of injury-induced osteoarthritis. Osteoarthritis and cartilage. 2005; 13(7):623-31.

61. Guzman RE, Evans MG, Bove S, Morenko B, Kilgore K. Mono-iodoacetate-induced histologic changes in subchondral bone and articular cartilage of rat femorotibial joints: an animal model of osteoarthritis. Toxicol. Pathol. 2003; 31(6):619-24.

62. Mundlos S, Olsen BR. Heritable diseases of the skeleton. Part I: Molecular insights into skeletal development-transcription factors and signaling pathways. FASEB journal : official publication of the Federation of American Societies for Experimental Biology. 1997;11(2):125-32.

63. Warnock JJ, Spina J, Bobe G, Duesterdieck -Zellmer KF, Ott J, Baltzer WI, et al. Culture of canine synoviocytes on porcine intestinal submucosa scaffolds as a strategy for meniscal tissue engineering for treatment of meniscal injury in dogs. Veterinary journal (London, England : 1997). 2014;199(1):49-56. 